\title{
Strengthening the integration of family planning and HIV services at the community level in Kenya
}

Wilson Liambila

Population Council

Sara Chace Dwyer

Population Council

Brian Mdawida

Charlotte E. Warren

Population Council

Melsa Lutomia

See next page for additional authors

Follow this and additional works at: https://knowledgecommons.popcouncil.org/departments_sbsr-rh

Part of the Demography, Population, and Ecology Commons, Family, Life Course, and Society Commons, Health Policy Commons, and the International Public Health Commons

How does access to this work benefit you? Let us know!

\section{Recommended Citation}

Liambila, Wilson, Sara Chace Dwyer, Brian Mdawida, Charlotte E. Warren, Melsa Lutomia, Jane Koech, Elizabeth Washika, and Aparna Jain. 2018. "Strengthening the integration of family planning and HIV services at the community level in Kenya," research report. Washington, DC: Population Council. 


\section{Authors}

Wilson Liambila, Sara Chace Dwyer, Brian Mdawida, Charlotte E. Warren, Melsa Lutomia, Jane Koech, Elizabeth Washika, and Aparna Jain 
Strengthening the Integration of Family Planning and HIV Services at the Community Level in Kenya

Wilson Liambila Sara Chace Dwyer Brian Mdawida Charlotte Warren
Melsa Lutomia

Jane Koech

Elizabeth Washika

Aparna Jain
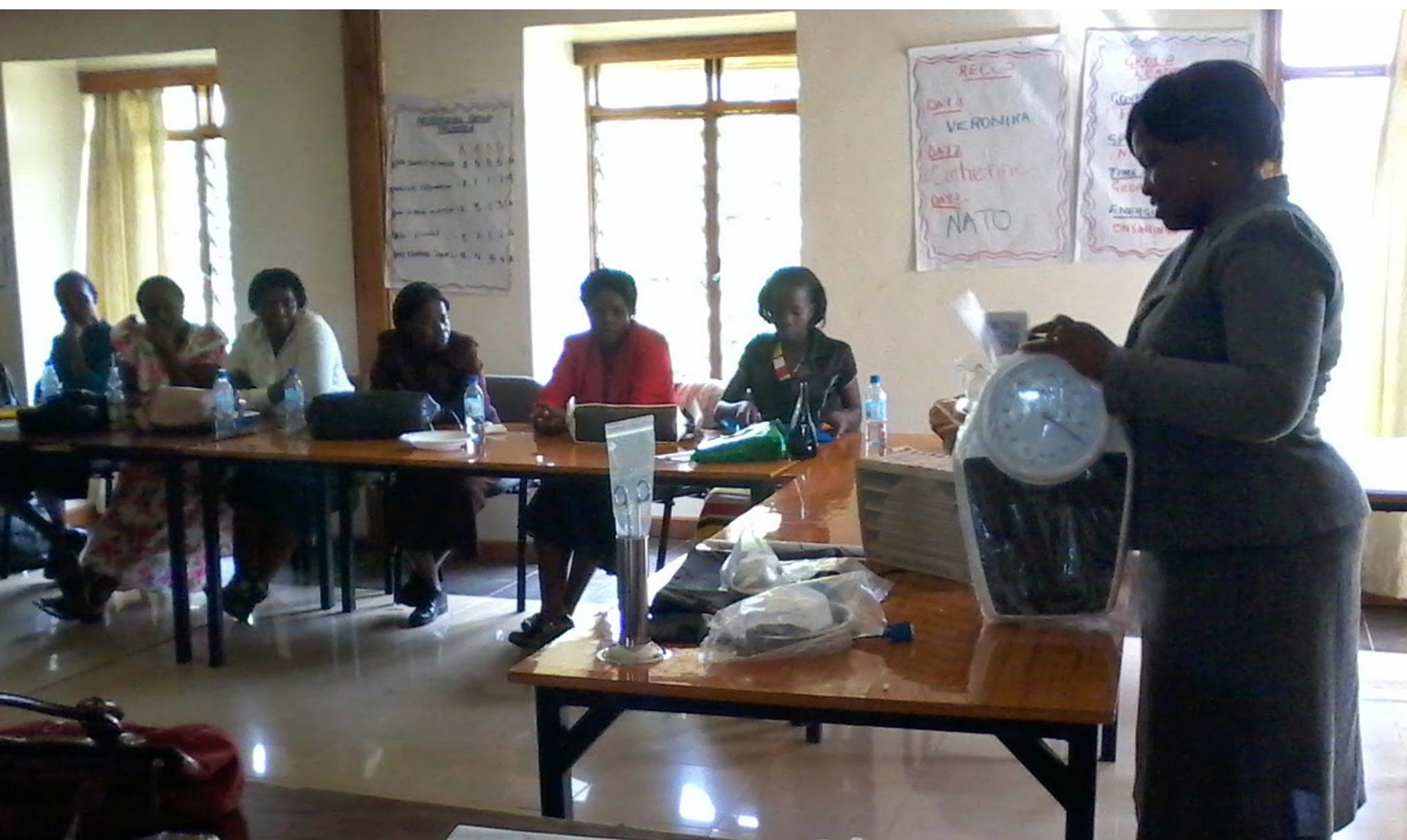


\section{The Evidence Project}

Population Council

4301 Connecticut Avenue, NW, Suite 280

Washington, DC 20008 USA

tel +1 2022379400

(3) USAID

The Evidence Project is made possible by the generous support of the American people through the United States Agency for International Development (USAID) under the terms of cooperative agreement no. AID-OAA-A-13-00087. The contents of this document are the sole responsibility of the Evidence Project and Population Council and do not necessarily reflect the views of USAID or the United States Government.

The Evidence Project uses implementation science-the strategic generation, translation, and use of evidence-to strengthen and scale up family planning and reproductive health programs to reduce unintended pregnancies worldwide. The Evidence Project is led by the Population Council in partnership with the Population Reference Bureau.

Published in February 2018.

Suggested citation: Liambila, Wilson, Sara Chace Dwyer, Brian Mdawida, Charlotte Warren, Melsa Lutomia, Jane Koech, Elizabeth Washika, and Aparna Jain. 2018. "Strengthening the Integration of Family Planning and HIV Services at the Community Level in Kenya," Research Report. Washington, DC \& Nairobi, Kenya: Population Council, The Evidence Project.

(c) 2018. The Population Council, Inc. 


\section{Strengthening the Integration of Family Planning and HIV Services at the Community Level in Kenya}

Wilson Liambila, Population Council, Nairobi

Sara Chace Dwyer, Population Council, Washington

Brian Mdawida, Population Council, Nairobi

Charlotte Warren, Population Council, Washington

Melsa Lutomia, Ministry of Health, Busia County

Jane Koech, Ministry of Health, Nairobi

Elizabeth Washika, Ministry of Health, Nairobi

Aparna Jain, Population Council, Washington

FEBRUARY 2018 


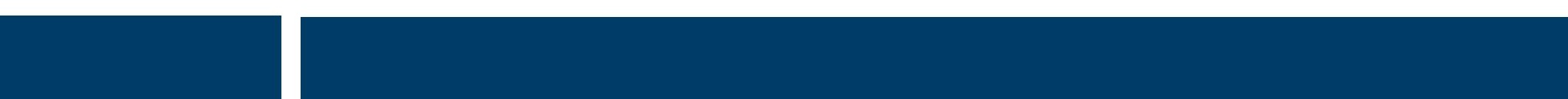




\section{Table of Contents}

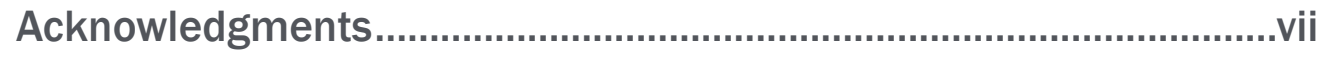

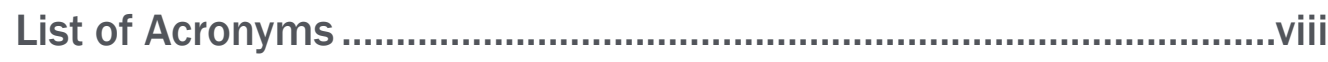

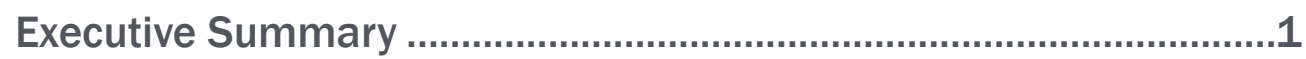

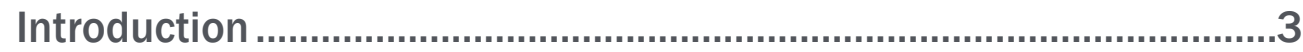

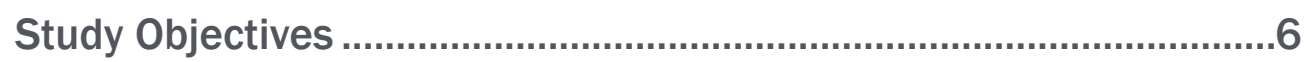

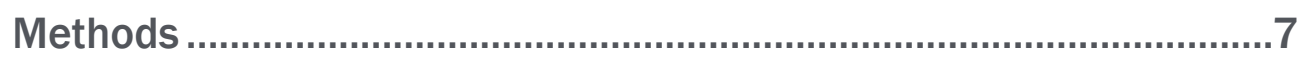

Description of the Intervention..........................................................11

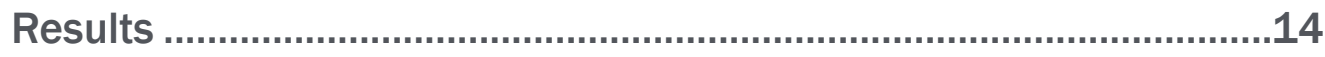

Findings from Observations of CHV-Client Interactions ..................................... 14

Results of Interviews with Community Health Volunteers................................... 18

Providers' Readiness to Support Integrated Services .......................................... 19

Community Unit Readiness For Integrated Services ........................................... 20

Clients' Experiences Using Integrated Services................................................. 21

Monitoring Of Interventions.............................................................................. 27

Cost Analysis And Incremental Costs For Integrated Services ........................... 27

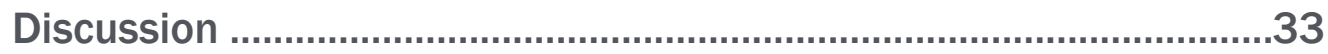

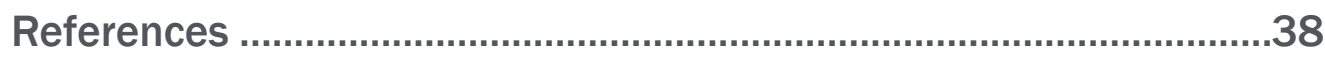




\section{List of Tables}

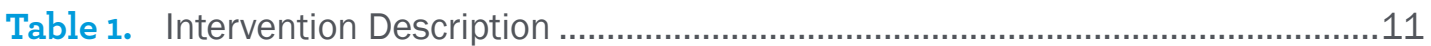

Table 2. Quality of Care in Observed CHV/Client Interactions at Baseline and Endline

Table 3. Proportion of CHV/Client Interactions Observed for Quality Counseling on STIs/HIV Treatment and Care at Baseline and Endline.

Table 4. Proportion of CHV/Client Interactions Observed for Quality of Care during Pre-FP Choice Counseling at Baseline and Endline.

Table 5. Proportion of $\mathrm{CHV} /$ Client Interactions Observed for Counseling on Specific FP Methods.

Table 6. Proportion of Interactions Where Clients Asked Questions and CHVs Showed Non-Judgmental Attitude at Baseline and Endline 17

Table 7. Aggregate Scores on Quality of CHVs Service Provision

Table 8. Interviews with CHVs Regarding Training and Service Provision at Baseline and Endline

Table 9. Proportion of HIV-positive respondents by background characteristics at baseline

Table 10. Percentage distribution of HIV-positive respondents' background characteristics at baseline

Table 11. Proportion of HIV-positive clients who reported being visited by a CHV in the last 6 months

Table 12. Proportion of HIV-positive clients using an FP method in the last 12 months

Table 13. Proportion of women who reported currently using an FP method at endline, by study arm...

Table 14. HIV-positive clients' preferences for using CHV services

Table 15. Proportion of clients who reported experiencing stigma and discrimination due to HIV

Table 16. Proportion of client responses during monitoring visits by study arm

Table 17. Results of test of difference in FP visits for FP arm and FP+ Business arm (paired t-test)

Table 18. Results of tests of difference in CHV visits for FP services for comparison site (paired t-test)

Table 19. Incremental costs during initial and subsequent years in FP arm and $\mathrm{FP}+$ Business arm 


\section{Acknowledgments}

This study was undertaken through a collaborative effort of various institutions and individuals whose input we wish to acknowledge.

The following officials are specifically thanked for having facilitated and taken part in the implementation of project activities in Busia County: Dr. Maurice Siminyu (County Executive for Health), Ms. Asumpta Matekwa (County Director of Nursing Services), Ms. Alice Yaite (Deputy County Director of Nursing Services), Mr. James Kuria (County Medical Records and Health Information Officer), Mr. Moses Magero (Deputy Medical Records Officer), Ms. Dorah Mutonyi (County Clinical Officer), Mr. John Mukoma (County Physiotherapist), Dr. Patroba Lukale (Samia Sub-county Medical Officer of Health), Ms. Winfred Mulamba (Samia Subcounty Public Health Officer), Mr. Emmanuel Luvai (County Community Strategy Focal Person), Mr. Dennis Wanjala (Samia Sub-county Reproductive Health Coordinator), and Mr. Wilberforce Were (Butula Sub-county Reproductive Health Coordinator).

We would also like to extend our gratitude to the sub-county health management teams in Samia and Butula sub-counties, facility management teams and in-charges in the two sub-counties, health providers, local nongovernmental organizations and community-based organizations, as well as research assistants for supporting research activities at different times and places in the study sites.

The support we received from Ministry of Health headquarters was invaluable. In view of this, we wish to particularly recognize the facilitation of Dr. S. Hussein (Head of the Community Health and Development Unit), Dr. Bartitol Kigen and Dr. Joel Gondi (former and current Head of Reproductive Health Services Unit at Ministry of Health Headquarters), and Dr. Jackson Kioko (Director of Medical Services - Republic of Kenya) for their support towards reproductive health/family planning/HIV integration activities in Kenya.

Special thanks go to Ms. Sheila Macharia (Senior Health Manager) and her colleagues at the USAID Kenya Mission for providing insights into the project activities at the initial stages of the study.

The project team sincerely appreciates the tireless efforts of Mr. Julius Majale, Florian Lugaliki, and Arnold Asava for their role in data cleaning and analysis, as well as Mr. Julius Korir who undertook costing analysis of the project interventions. Similarly, we appreciate the roles played by Ms. Janet Munyasya and Ms. Joyce Ombeva of the Population Council Nairobi office for providing administrative support to the project activities in a timely manner. Mr. Zeka Wekesa is thanked for generating tables and figures from the findings as well as editing this research report.

We would like to thank the county administration officers, community health volunteers, and clients for agreeing to participate in this study.

We wish to most sincerely acknowledge the Evidence Project team at the Population Council, namely, Laura Reichenbach and Karen Hardee for reviewing the study protocol and project report as well as providing overall technical support to the project.

Finally, we wish to acknowledge and appreciate the technical and financial support of the Interagency Working Group, USAID, especially Tabitha Sripipatana and Jennifer Mason, and the President's Emergency Plan for AIDS Relief (PEPFAR). 


\title{
List of Acronyms
}

\author{
AIDS Acquired Immune Deficiency Syndrome \\ ART Antiretroviral Therapy \\ BCS Balanced Counseling Strategy \\ CBO Community-based organization \\ CCC Comprehensive Care Centre \\ CHEW Community Health Extension Worker \\ CHMT County Health Management Team \\ CHV Community Health Volunteer \\ CU Community Unit \\ FGD Focus Group Discussion \\ FP Family Planning \\ HIV Human Immunodeficiency Virus \\ HMT Health Management Team \\ IDI In-Depth Interview \\ KII Key Informant Interview \\ MCH Maternal and Child Health \\ $\mathrm{MoH} \quad$ Ministry of Health \\ PEPFAR President's Emergency Plan for AIDS Relief \\ RH Reproductive health \\ SCHMT Sub-County Health Management Teams \\ SRH Sexual and Reproductive Health \\ STI Sexually Transmitted Infection \\ USAID United States Agency for International Development
}




\section{Executive Summary}

Studies have shown that the rate of unintended pregnancies among women living with HIV in low- and middleincome countries is high. This project sought to gather evidence of the feasibility, quality of care, acceptability, and effectiveness of using Community Health Volunteers (CHVs) to integrate family planning (FP) into HIV/ AIDS services for women living with HIV at the community level in Busia County, Kenya.

The primary objectives of the study were to assess: (i) whether training CHVs to integrate FP counseling in existing community-level HIV services increases FP use among HIV-positive women (ii) whether training of community health committees (CHCs) in business skills and income generation increases the retention of CHVs and provision of quality health services; and (iii) the differences in FP use across intervention arms, relative to the comparison arm. A secondary objective of the study was to measure the incremental financial costs of training $\mathrm{CHVs}$ in $\mathrm{FP} / \mathrm{HIV}$ integration services.

The study employed a quasi-experimental before-and-after research design with a comparison site. A three-arm study (FP arm, FP+ Business arm and comparison arm) was employed to test the effectiveness of a package of interventions on FP use among HIV-positive women. The FP and FP+ Business arms were implemented in Samia sub-county and the comparison arm was implemented in Butula sub-county. The FP arm (included a 5-day training on integrating FP into HIV services for CHVs) was implemented in 15 Community Units (CUs), while the FP+ Business arm (the same 5-day FP training in addition to a business skills training for CHC members) was implemented in 14 CUs. Butula had similar socio-economic indicators as Samia, making it a reasonable comparison site. The study population comprised CHVs, women living with HIV ages 18-49, $\mathrm{CHCs}$, healthcare providers, county health management teams, and opinion leaders.

Implementation of the intervention package entailed sensitization of national and county-level stakeholders, sensitization of facility managers and community health extension workers, review and development of training materials and job aids, training of CHVs in FP and FP+ Business arms, strengthening the capacity of CHC leadership teams in business skills, conducting supportive supervision, and monitoring project progress.

Data collection for the study was undertaken in two formats. The qualitative component involved key informant interviews with opinion leaders, in-depth interviews with county and sub-county health management teams, and focus group discussions with women living with HIV. The quantitative component involved observations of CHV-client interactions, interviews with CHVs on training and service provision, interviews with health facility-based providers, interviews with $\mathrm{CHCs}$ to assess the $\mathrm{CU}$ readiness, and interviews with women living with HIV.

The study findings demonstrate:

Improvement in provision of quality integrated FP/HIV services by $\mathrm{CHVs}$ at community level

- Based on total composite score results from the client-CHV observations, the overall quality of CHV service provision was low at endline but improved from baseline in the FP and FP+Business arms.

- The proportion of CHVs who showed confidence in integrating FP/HIV activities increased significantly, from 8 percent to 43 percent in the FP arm $(\mathrm{p}<0.01)$ and from 19 percent to 53 percent in $\mathrm{FP}+$ Business arm $(\mathrm{p}<0.01)$. Changes in the comparison arm were not significant.

\section{$\mathrm{CHV}$ retention and reporting rates were different in the three study sites}

- There were significant differences in CHV retention rates as measured by CHV monthly reporting between the comparison site and FP+ Business arm before and after the intervention. 
Mixed results on providers' readiness to support provision of integrated services at community level

- Integration of FP and HIV services at the community level was acceptable to health providers assessed during the study. The majority of the providers said they were supportive of reproductive health, FP and HIV integration activities. All providers said that clients seeking Antiretroviral Therapy/Comprehensive Care Center services were counseled on FP services.

- At endline, all providers indicated that they had never observed fellow healthcare workers unwilling to care for clients living with HIV. However, the findings showed that a number of providers still held discriminatory attitudes towards persons living with HIV.

\section{Community Unit's functionality supports integrated services}

- Overall, CUs in all three study arms had good cardinal functionality at endline when compared to baseline. For instance, the number of CUs who had at least 80 percent of their CHVs regularly reporting on community activities and visits increased from 16 out of 22 at baseline (72 percent) to 43 out of 50 at endline (86 percent). The number of CUs whose CHCs held monthly feedback meetings in the three months preceding the survey increased from 19 out of 22 at baseline ( 86 percent) to 45 out of 50 CUs at endline (90 percent). The number of CUs that reported their CHC members held Health Action Days each month in the last three months increased from 12 out of 22 at baseline (55 percent) to 33 out of 50 at endline (66 percent).

\section{Clients' experience in use of integrated services was satisfactory}

- There was a significant increase in the proportion of clients who used a FP method in the 12 months preceding the endline survey, compared to baseline, in all the study arms.

- The proportion of clients who were comfortable with CHVs bringing FP methods to them in the community increased from 71 percent at baseline to 90 percent at endline $(\mathrm{p}=<0.01)$ in the FP+ Business arm, but also from 73 percent to 85 percent $(\mathrm{p}=<0.05)$ in the comparison arm. In addition, the proportion of clients who were visited by CHVs in the 6 months preceding the survey increased significantly across all study arms.

\section{Cost analysis for integrated service provision}

- The annual incremental cost per CHV during the initial year would be US\$181.74 and US\$121.55 in the subsequent year.

- The incremental cost to scale-up integrated services in 184 CUs in Busia County in the initial year would be approximately US $\$ 501,602.40$, and the subsequent recurrent annual costs would be US $\$ 335,478.00$.

In conclusion, this study demonstrated that CHVs have the potential to integrate FP services into their regular service provision to women living with HIV. However, the findings showed mixed results in some areas, indicating that additional support and review of the training may be needed to prepare CHVs with the knowledge and skills to provide integrated services. Key programmatic recommendations for integrated FP/ HIV services at community level are:

- Training of CHVs in integrated FP/HIV should be evaluated to see how it could improve quality of CHV provision of integrated services. Greater attention should be placed on enhancing the quality of care provided by the CHVs and equipping them with necessary reporting tools and FP commodities.

- Effective referral systems need to be put in place between the community and link health facilities, and within departments in the facilities.

- Strategies for reducing HIV-related stigma and discrimination should be incorporated in the in-service training for healthcare providers. 


\section{Introduction}

\section{Background}

According to UNAIDS, at the end of 2010 an estimated 34 million people were living with HIV, and subSaharan Africa continued to be disproportionately affected by the epidemic, with about 68 percent of all people living with HIV residing in the region. Women account for over half (59 percent) of all people living with HIV globally. ${ }^{1}$ With major efforts directed at expanding access to life-saving antiretroviral therapy (ART) in subSaharan Africa ${ }^{2}$, many people on ARTs are now able to lead productive and sexually active lives and as a result, may face the possibility of having an unintended pregnancy. ${ }^{3}$ For women living with HIV, the likelihood of adverse health outcomes associated with pregnancy are elevated due to a number of factors, including faster decline in CD4 count after pregnancy, HIV-related infections and co-morbid conditions like diabetes. ${ }^{4,5,6,7,8,9}$

Studies in Kenya and Malawi found that 54 percent and 40 percent of women living with HIV, respectively, reported that their last childbirth was unintended, and modern contraceptive use was lower among HIV-positive than HIV-negative women (26 percent vs. 46 percent in Kenya; 19 percent vs. 46 percent in Malawi). ${ }^{10}$ Other data from Kenya (specifically, the Kenya AIDS Indicator Survey), and from Swaziland showed little difference in contraceptive use between HIV-positive and HIV-negative women. ${ }^{11,12,13}$

Enabling women living with HIV to use contraception effectively is a cost-effective strategy that can decrease the number of unintended pregnancies and in turn can reduce maternal mortality and vertical transmission of HIV..$^{14,15,16,17,18,19,20}$ However, this strategy is undervalued and not fully appreciated by those responsible for implementing sexual and reproductive (SRH) and HIV programs. ${ }^{21}$ Prevention of unintended pregnancies among women living with HIV has been identified as one of the major components of a comprehensive strategy on prevention of mother-to-child HIV transmission. ${ }^{22}$ The FP2020 partnership goal to enable 120 million more women and girls to access modern contraceptives by 2020 acknowledges the urgency of identifying and implementing interventions that will help all women meet their contraceptive needs. ${ }^{23}$ Respecting client rights and informed choice, especially for HIV-positive women, including the ability to control one's fertility through access to contraception, are key considerations that need to be taken into account while providing SRH services.

Community health volunteers (CHVs) are a growing force for extending health care and improving the health of populations, particularly in rural and hard-to-reach areas. ${ }^{24}$ Evidence from community-based regional studies and systematic reviews of integrating family planning (FP) and HIV services reveal that CHVs contribute to major improvements in priority health areas, including improving maternal and child health $(\mathrm{MCH})$, expanding access to FP services, and contributing to the control of HIV, malaria, and tuberculosis. Furthermore, evidence from a systematic review of interventions linking FP and HIV services finds that using CHVs in providing integrated FP and HIV services is both feasible and effective. ${ }^{25,26,27,28}$

\section{Project Rationale}

While information and data on the outcomes of integrating HIV services into FP and reproductive health $(\mathrm{RH})$ services are readily available, less is known about the integration of FP into HIV services, especially at the community level. For instance, a recent review of studies that focused on integrating FP into HIV care and treatment services identified the need for more evidence of its effects on unintended pregnancies and costeffectiveness, as well as a need for better reporting of process outcomes of this approach. ${ }^{29}$ 
This study addressed an important intervention gap in RH/HIV generally and FP/HIV integrated services specifically. Previous studies in Kenya focused on integrating FP into voluntary counseling and testing services using lay counsellors, ${ }^{30}$ or integrating counseling and testing for HIV within FP services in health facilities. ${ }^{31}$ Furthermore, previous studies that sought to integrate FP within HIV services were mainly implemented within static health facilities ${ }^{32,33}$ and not at the community level. Hence there was a need to identify the types of FP/ HIV service integration activities that work at the community level.

According to the National RH and HIV Integration Strategy, the goal of integrated services is to provide more comprehensive, convenient, acceptable, and cost-effective RH and HIV programs. The integration of FP and HIV services is highlighted in Kenya's Reproductive Health and HIV Integration Strategy of $2009^{34}$ as well as the minimum RH/HIV Integration Package of 2012 (Box 1). These documents seek to provide guidance to implementers and service providers on the minimum requirements in terms of infrastructure, human resources, skills set and training materials, equipment, commodities and supplies, and monitoring and evaluation that are necessary for effective service provision at any level of care. ${ }^{35}$

\section{BOX 1}

Minimum package of RH/HIV integrated services in Kenya

Integrated community-based RH/HIV services

- FP information and counseling, provision of condoms, pills, and referral for other FP methods;

- Information on HIV prevention, referral for counseling and testing, antiretroviral therapy (ART) adherence, and psychosocial support;

- Information on sexually transmitted infections (STIs), reproductive tract infections, cervical, prostate and breast cancers, sexual and gender based violence (SGBV), tuberculosis (TB), voluntary medical male circumcision services, female genital mutilation/cutting (FGM/C) and referrals;

- Information on infection prevention, maternal, newborn and child health, including Prevention of Mother-to-Child Transmission of HIV.

Facility-based RH/HIV integrated services

- Outpatient services-STIs, TB, Sexual and Gender Based Violence screening, provider initiated testing and counseling (PITC), reproductive organ cancer screening;

- MCH/FP unit services-including focused antenatal care (FANC), post-natal care and FP, maternity (includes labor and delivery and post-natal wards), early infant diagnosis (EID);

- Inpatient ward services-including HIV counseling and testing, comprehensive post-abortion care (PAC), TB screening, information on FP, STI/RTI (reproductive tract infection), reproductive organ cancer screening;

- Comprehensive Care Centre (CCC) services-including FP services, STI screening and treatment, information and screening for reproductive organ cancer, TB screening, psychosocial support;

- Youth friendly service sites - provision of information, counseling and FP methods, HIV testing and counseling (HTC), STI screening services, reproductive organ cancer screening, comprehensive Sexual and Gender Based Violence services, provision of antiretroviral (ARV), and services to address opportunistic infections (OI), substance abuse, focused antenatal care and post-natal care.

Cross-cutting themes

- These include: Administration support, supportive supervision, referral mechanisms and human resources. 
In a study conducted by the Population Council with support from USAID (through the Global Health Division), results showed that in addition to their acquisition of technical skills, CHVs and other mid-level professionals could benefit from knowledge in financial literacy and business skills. ${ }^{36} \mathrm{CHC}$ members would benefit from such skills, as they are responsible for coordinating and managing community-based healthcare activities that include mobilizing resources and developing income generating activities. The study recommended that business skills training should be included in all future CHC capacity building, as it would offer them the financial knowledge to sustain and expand healthcare operations at the community level.

\section{Organization of Community Health Microsystem}

This study was implemented within Kenya's existing community level healthcare governance structure, which are summarized in Box 2.

\section{BOX 2}

Community-level healthcare governance structures

- Community unit (CU): Consists of approximately 5,000 people with about 1,000 households, and is managed by a CHC. Each CU has approximately 15 CHVs and is linked to the nearest health facility in the catchment area.

- Community health committee (CHC): This is the management arm of the CU, consisting of elected officials and ordinary members, for a total of 13 members. The officials include a chairperson drawn from the local community, a secretary who is a field-based community health extension worker (CHEW), and a treasurer who is a community health volunteer (CHV) or a community member. $\mathrm{CHC}$ members, as the managers of CUs, are responsible for key activities including managing communitybased activities, local policy formulation, resource mobilization and managing income generating activities for purposes of sustaining the CU operations.

- Community heath extension workers (CHEWs): There are two types of CHEWs:

1. Facility-based CHEWs receive reports from community-based CHEWs, receive and process clients referred to the facility by CHVs, provide supplies to CHVs, organize community outreach activities and undertake defaulter tracing.

2. Community-based CHEWs are in charge of all community-based health activities including supervision of $\mathrm{CHVs}$, facilitation of community dialogue days and reporting of health activities.

- Community health volunteers (CHVs): CHVs are the technical members of the CU responsible for providing preventive, promotive, and limited curative health services. CHVs report to CHEWs on technical matters including submitting reports of healthcare activities undertaken in any given month. At the same time, the CHVs report to $\mathrm{CHCs}$ on administrative matters such as field transportation, security, and number of households to be served.

- Health facilities are managed by either a Hospital Management Team (HMT) if it is a hospital or a rural Health Facility Management Team (HFMT) if it is a health center or dispensary. HMTs and HFMTs in turn report to Sub-County Health Management Teams that ultimately report to the County Health Management Team. 


\section{Study Objectives}

The purpose of the study was to generate evidence that can inform the strengthening of FP and HIV integrated services at the community level in Busia County, Kenya through the use of CHVs.

The primary objectives of the study were to:

1. Assess whether training CHVs to integrate FP counseling in existing community-level HIV services increases FP use among HIV-positive women;

2. Assess whether training of CHCs in business skills and income generation increases the retention of CHVs and provision of quality health services; and

3. Assess the differences in FP use across intervention arms relative to the comparison arm.

The secondary objective of the study was to measure the incremental financial costs of training CHVs in FP and CHCs in business skills/income generation to inform possible replication and scale-up. Methods and results of the cost analysis will be presented separately after the results section. 


\section{Methods}

\section{Study Design}

A quasi-experimental before-and-after, three-arm study was implemented in Busia County, Kenya. Two arms included interventions (FP arm and FP + Business arm), while the third arm was a comparison. The study was designed to assess the effect of integrating FP counseling into existing HIV services offered by CHVs on FP use by HIV-positive women.

\section{Study Population}

Four populations were surveyed: 1) women living with HIV, 2) CHVs, 3) CHCs, and 4) health care providers. A cohort of women living with HIV, between the ages of 18 and 49, were surveyed at two timepoints: before the intervention was implemented (baseline) and after the intervention ended (endline). Potential respondents were identified by CHVs through HIV support networks. Respondents were informed about the study and - if interested - referred to a trained data collector who provided more information about the study and obtained informed consent. At endline, a sub-set of women living with HIV were invited to participate in Focus Group Discussions (FGDs) to: (i) determine local perceptions and support for integrated FP/HIV services; (ii) perceptions of service quality; and (iii) stigma and discrimination associated with being HIV-positive. The FGDs were administered in two categories -among women between 18 and 24 years old, and among women 25 years and older.

CHVs were recruited by $\mathrm{CHC}$ officials and community health extension workers (CHEWs). The eligibility criteria for CHV participation was: regular and consistent reporting of community-based health care activities; respected by other CHVs and the local community; and experience working with HIV-positive clients or participating in home-based care activities.

In the FP and FP+ Business arms, all CHVs (324) were trained on the integration of FP into HIV services. All participating CHVs were interviewed at baseline and endline to assess their level of interactions with clients during consultations; their counseling skills on Sexually Transmitted Infections (STIs) and HIV care and treatment; provision of FP services before, during and after selecting method of choice; their skills and training on integrated FP/HIV services; as well as broader issues on attitudes towards the delivery of integrated FP/ HIV services at community level. A sub-group of participating CHVs was also included in the observational checklist at baseline $(\mathrm{n}=212)$ and endline $(\mathrm{n}=176)$. Immediately after observations of client-CHV interactions, research assistants asked CHVs to remain and participate in a short interview, after releasing their clients. During the interview, the research assistants obtained information on the demographic and socio-economic characteristics of the CHVs as well as in-service training in FP and other reproductive health services they have received.

Fifty Community Units (CUs) in Busia County were assessed for readiness to support CHVs who adopted FP integration activities into HIV/AIDS services. CHCs, CHEWs, and randomly selected CHVs were interviewed in each selected $\mathrm{CU}$ at baseline and endline to determine $\mathrm{CU}$ readiness. Providers working in the MCH-FP and ART units of public health facilities located within Busia County were asked to participate in the study. Although the study was focused on CHVs, the inclusion of facility-based health providers was important, given the referral linkage between CHVs and health facilities. Providers were interviewed at baseline and endline to assess their knowledge and current practices related to integration of FP, STI and HIV/AIDS services. 


\section{Study Sites}

The study was implemented in Samia and Butula sub-counties of Busia County located in south western Kenya. Figure 1 is a map of Busia County showing the intervention (Samia) and comparison (Butula) sites. Samia was purposively chosen as an intervention site for the FP and FP+ Business arms based on recommendations from the Ministry of Health $(\mathrm{MoH})$. The $\mathrm{MoH}$ had completed a pilot project in Samia that sought to strengthen the health management information system using an mHealth platform, and the $\mathrm{MoH}$ felt that this study would provide an opportunity to build on the operations of that platform. Butula sub-county was selected as a comparison site based on its similar socio-economic indicators to Samia.

\section{FIGURE 1. MAP OF THE STUDY SITE}

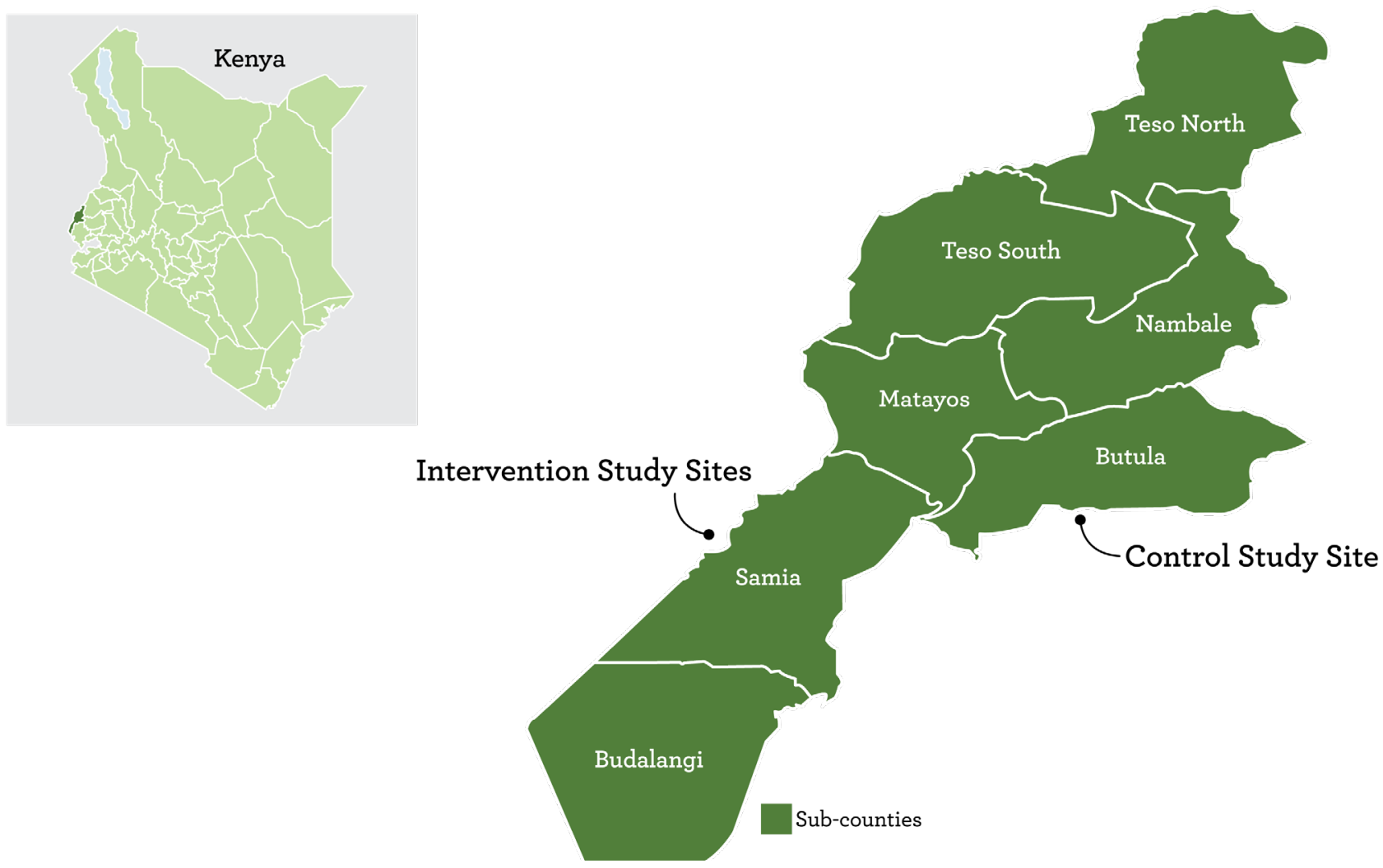

\section{Data Collection}

\section{Formative research}

Formative research was conducted in November and December 2015 (before baseline data collection) to understand the local context, gain information on current County Health Program activities, and understand the sexual behaviors and contraceptive needs of women living with HIV. Key informant interviews with religious and opinion leaders, and in-depth interviews with the sub-county health management (SCHMT) teams were conducted to understand the variety of issues around integrated FP/HIV services at the community level. FGDs were held with women living with HIV and with CHVs in a non-study site (Matayos sub-county) to ensure that the study team used the right terminology and focused on priority issues that prevent women living with HIV from accessing care and services. The results of these interviews informed the design of the quantitative tools, the FP and FP+ Business intervention arms, and requisite training materials. 


\section{Data collection tools for baseline and end line}

Data collection was undertaken using the following tools in both intervention and comparison sites:

- Observation tool: This tool was administered by research assistants both at baseline and endline to observe the interaction between a CHV and his/her client. The purpose of the tool was to assess the feasibility, acceptability, and quality of care of the interventions. The tool covered FP counseling (pre-choice stage, method choice stage and post-choice stage); HIV/STI activities; screening for other services; and overall assessment on FP/HIV integration activities.

- Community scorecard: This tool was administered by research assistants to officials of village health committees at baseline and endline. The purpose of the tool was to assess basic functionality (process, performance and cardinal) indicators of CUs based on the Ministry of Health's National Community Health Strategy. The functionality indicators were used to gauge how well the CU was performing in terms of resource availability, programming and routine operations.

- Health provider tool: This tool was administered by research assistants at both baseline and endline to health providers working in MCH/FP and HIV-AIDS units in health facilities located within catchment areas of community health units. The purpose of the tool was to help gather information on the extent to which health facilities supported CUs and health volunteers in terms of training, supervision, reporting, referral and logistics including provision of drug kits, and FP and HIV commodities.

- Women living with HIV tool: This tool was administered by research assistants to women living with HIV, in their household, at baseline and endline to assess the acceptability and effectiveness of the interventions and, in particular, the extent to which they received integrated services at the community level.

- Guides for conducting FGDs/KIIs/IDIs: These guides were used by research assistants to conduct FGDs with women living with HIV at both baseline and endline, and with CHVs at baseline only. A key informant interview (KII) guide was used to interview religious and opinion leaders at baseline. An indepth interview (IDI) guide was used to interview CHMT and SCHMT at baseline.

- Costing tool: This tool was administered by research assistants to CHVs at baseline and endline to estimate the additional health system resources required to integrate FP into HIV services at the community level.

In addition to the data collection instruments, data on CHV monthly reporting were received from all CUs in the three study arms.

\section{Research assistant training}

Research assistants participated in a six-day training to ensure guidance on ethical conduct and the study tools were clearly understood. The first training was conducted in November 2015 and focused on the baseline surveys for HIV-positive women, CHC members, health providers and CHVs, in addition to the CHV-client observation tools. The training included focused sessions and exercises on the meaning and process of informed consent, the importance of protecting the subject's privacy, and how to ensure confidentiality. A second training for the same team of research assistants to undertake the endline survey was conducted for six days in November 2016 and covered the same topics while incorporating lessons learned from the baseline. Both trainings were led by Population Council staff and Busia CHMT teams.

Baseline surveys and observation checklists were conducted in December 2015 before any interventions were implemented. The same tools were administered at endline in December 2016. All surveys and observations 
were completed in person. Client surveys were conducted in the clients' homes and the client-CHV interactions were observed in a location designated by the client, to ensure their privacy and comfort were respected.

Research assistants who conducted the observation checklist had a clinical background in order to correctly identify proper behavior and attitudes during the CHV-client interaction. Informed consent was received from all study participants before the start of each baseline and endline observation and survey.

\section{Field data collection}

All interviews were conducted in private. Identifying details were not included during data collection, data entry or analysis. Supervision of data collection in the field was undertaken by the Head of Data Management Unit at Population Council/Kenya, assisted by two supervisors recruited for the purpose.

\section{Data Management and Analysis}

All data collection instruments contained an identification number and were kept under lock and key at all times in the field, and were then transferred to locked file cabinets in the Population Council's Nairobi office. As standard practice, informed consent forms were stored separately in a locked cabinet to avoid linking them to identifying information contained in the filled data collection instruments. Only key project staff had access to the completed informed consent forms.

Quantitative data were collected using Android-enabled phones and submitted to a central server daily. The research team transferred data from the central database to SPSS version 19 and simple tabulations were completed to check for data consistency, completeness, and to prepare the data for final analysis.

Descriptive analyses, chi-square tests and Kruskal-Wallis test were used to determine significant associations between baseline and endline in each study arm. For means, paired T-tests were used to ascertain significant differences. Chi-square tests, using CHV monthly reporting data from CUs, were used to determine significant associations between differences in CHV the average monthly reporting between the three intervention arms. The comparison focused on the consistency, accuracy and timeliness of the CHVs' reporting on community health activities based on Ministry of Health Guidelines on functionality of CUs.

FGDs with women living with HIV were tape-recorded, transcribed using Microsoft Word software, and translated into English when appropriate by a data collector familiar with local languages.

\section{Ethical Review}

The study protocol, including study tools and informed consent forms, was reviewed and approved by the Population Council's Institutional Review Board (IRB No. 702 of August 2015) and the Kenyatta National Hospital/University of Nairobi Ethics Research Committee (No. P573/08/September 2015). Written consent was obtained from all respondents in this study prior to the start of each data collection activity. 


\section{Description of the Intervention}

Key intervention activities commenced in September 2015 and included: 1) a series of meetings with the MoH at the central, county and sub-county levels to sensitize stakeholders to the project, and ensure their commitment and participation in the intervention design; 2) reviewing and adapting an orientation training package on community FP/HIV integration, including job aides; 3) training CHVs in FP/HIV integrated services; and 4) orienting CUs in business skills for sustainability and support to CHVs. There were two intervention arms: the FP arm integrated FP into HIV services in $15 \mathrm{CUs}$, and the FP + Business Arm integrated FP into HIV services in 14 CUs whose CHCs had been equipped with business skills. The intervention activities are described in Table 1.

\section{TABLE 1. INTERVENTION DESCRIPTION}

\begin{tabular}{|c|c|c|}
\hline Activity & Detail & Targets Achieved \\
\hline Meetings with $\mathrm{MoH}$ & $\begin{array}{l}\text { From September to November } 2015 \text {, sensitization meetings were } \\
\text { held at the national level and with the county and sub-county } \\
\text { health management teams (CHMT and SCHMTs), non-governmental } \\
\text { organizations (NGOs), community-based organizations (CBOs), and } \\
\text { health facility managers. The purpose was to agree on the scope of } \\
\text { the study, clarify roles among partners, discuss the study intervention, } \\
\text { engage with stakeholders and obtain their inputs into the intervention } \\
\text { design and foster their continued buy-in. The county level meetings } \\
\text { were held in October and November } 2015 \text { and were coordinated by the } \\
\text { CHMTs and SHMTs teams in their respective study sites. }\end{array}$ & $\begin{array}{l}\text { - } 2 \text { Divisions within } \\
\text { the MOH HQRs } \\
\text { - } 1 \text { CHMT } \\
\text { - } 2 \text { SCHMTs } \\
\text { - } 2 \text { NGOs \& CBOs } \\
\text { - } 29 \text { CHEWs }\end{array}$ \\
\hline
\end{tabular}

In December 2015 and January 2016, the research team, in collaboration with the CHMTs, reviewed and adapted existing CHV training materials and job aides on integrating FP into care and treatment services for HIV-positive clients. The materials included the Kenya Community Health Strategy, the balanced counseling strategyplus (BCS+) toolkit, the CHVs training and participant manuals, as well

Review of existing training materials, job aides and forms as household registers, reporting forms, a commodity tracking tool and the CHV referral form.

Following the review, several topics were updated including: counseling clients for FP services; referrals for FP methods; recognizing HIV stigma and discrimination; ways to minimize HIV stigma and discrimination; and provision of FP in the context of clients' rights and informed choice. To strengthen counseling skills, a community version of the BCS+ was adapted by the $\mathrm{MOH}$ for use in the intervention study sites in Samia sub-county.

The training of CHEWs in the FP and FP+ Business arms was conducted in February 2016 by the CHMT and the Samia SCHMT. The overall goal for the training was to equip CHEWs with the necessary knowledge, skills and attitudes to enable them train $\mathrm{CHV}$ s to effectively integrate FP and HIV services at the community level.

Training of community health extension workers (CHEWs)
The topics covered included: Key roles and responsibilities of CHVs; importance of integrating FP and HIV services at the community level; ways of reducing stigma and discrimination among people living with HIV; FP methods; basic counseling skills in the provision of FP methods at the community level using BCS+; rumors, myths and misconceptions related to common FP methods; role plays on how to integrate FP and HIV services using the BCS+ at the community level; and the importance of documentation and record keeping in the provision of FP services.
8 training materials reviewed 


\begin{tabular}{|c|c|c|}
\hline Activity & Detail & Targets Achieved \\
\hline $\begin{array}{l}\text { Training of CHVs in } \\
\text { FP and FP + Business } \\
\text { Arms }\end{array}$ & $\begin{array}{l}\text { CHVs in the FP and FP+ Business arms received a five-day training } \\
\text { on provision of integrated FP and HIV services, with an emphasis } \\
\text { on upholding informed choice and clients' rights. The trainings were } \\
\text { conducted by CHEWs, who were trained in the preceding week, and } \\
\text { were spread over a 2-week period in February 2016. Trainings took } \\
\text { place at } 11 \text { local venues in Samia sub-county, and a total of } 324 \text { CHVs } \\
\text { were trained. The topics included: } \\
\text { - FP counseling using the community version of the BCS+ } \\
\text { - Provision of short-acting FP methods, such as condoms and pills } \\
\text { - Referral to facilities for voluntary use of long-acting reversible } \\
\text { contraception (LARC) or permanent methods } \\
\text { - Routine provision of FP services among clients seeking HIV testing } \\
\text { - HIV treatment and care and routine HIV information and education, } \\
\text { and risk assessment } \\
\text { - Information on the provision of HIV services and training } \\
\text { - Dtigma and discrimination } \\
\text { CHVs took part in a pre/post-test to assess their level of knowledge } \\
\text { before and after the training. The pre-test mean score was } 46 \text { percent, } \\
\text { with a range of } 33 \text { - } 54 \text { percent, while the post-test mean score was } 67 \\
\text { percent, with a range of } 50 \text { - } 84 \text { percent, translating into a } 46 \text { percent } \\
\text { increase in the mean score. }\end{array}$ & $\begin{array}{l}324 \mathrm{CHVs} \text { trained } \\
(170 \text { in FP arm } \\
\text { and } 154 \text { in FP + } \\
\text { Business arm) }\end{array}$ \\
\hline
\end{tabular}

CHC members 2-day training in business skills in FP+ Business Arm
Eighty-four CHC members from 14 CUs participated in a two-day training in business skills and income generation. The training took place in two sessions in late February 2016 at a local hotel. Business skills were intended to enable $\mathrm{CHCs}$ to generate income to support the operations of CUs, including funding of community level meetings, education and awareness campaigns, and transportation costs for $\mathrm{CHVs}$ when undertaking community health related functions, among other activities. The content of this training was based on Population Council's successful history of working with CBOs in business activities in Kenya and was tailored to build the capacity of $\mathrm{CHC}$ members in developing and running income generating activities for the CU. The training included the following topics:

- Scope of sustainable livelihoods, marketing and market development

- Household enterprise development

- Customer care and value addition for enterprise development

- Generating business ideas, scope of trading within the community

- Livelihoods and enterprise development

- Basic record keeping and business records

- Resource mobilization for business start-up, debt and credit management

- Financial literacy

- Group dynamics and enterprise development

- How to manage successful Income Generation Activities, and action planning.
$84 \mathrm{CHC}$ members trained (from 14

CUs) 


\section{Intervention Monitoring and Support Supervision}

Monitoring and supportive supervision activities were conducted to track the implementation of interventions.

\section{Monitoring}

Monitoring was undertaken to assess the extent to which the interventions were being implemented. The monitoring was carried out by research assistants who interviewed respondents twice, at the beginning of the study (Round 1 in March-April 2016) and towards the end of the study (Round 2 in July-August 2016). In Round 1, research assistants obtained information from 441 HIV-positive clients in the comparison arm, 476 in the FP arm and 312 in the FP+ Business arm. During Round 2, the research assistants obtained information from 444 HIV-positive clients in the comparison arm, 400 in the FP arm and 360 in the FP + Business arm.

The first phase of monitoring coincided with the finalization of trainings, while the second phase of monitoring was the mid-point of the intervention implementation period. Information collected included health providers' visits to women living with HIV, types of services given by providers, and family planning methods given by providers.

Research assistants monitored the activities of $26 \mathrm{CUs} / \mathrm{CHCs}$ in the intervention and comparison sites in Round 1 (March-April 2016,) and of 22 CUs/CHCs in Round 2 (July-August 2016). The monitoring of CUs/ CHCs took place after the training on business skills. The key activities monitored included proportion of CUs with business plans, number of CU members with knowledge in book keeping and skills in filling a cash book, and number of monthly reports shared with other CHMT staff. Requirements for the monthly and quarterly reports were: CUs with records showing an increase in income, CUs with knowledge in developing savings and investment plans, marketing strategies for their Income Generation Activities products, increasing income, reducing operational costs of their businesses as well as those CUs that had developed expansion plans for their businesses and sharing records of their workload (in terms of home visits and follow-ups).

\section{Supportive supervision}

Busia County and Samia sub-county health management teams (HMTs) were updated in supportive supervision and monitoring to ensure $\mathrm{CHVs}$ retained the skills gained during the training, ensure quality provision of integrated FP/HIV services, and to build the capacity of CHEWs (who oversee CHV activities) in supportive supervision. Supervision was conducted quarterly by the County and sub-county HMTs. For sustainability purposes, supportive supervision activities were implemented within the $\mathrm{MoH}$ framework, which requires that supportive supervision at various levels of the healthcare system be carried out by institutions, persons or groups that have a reporting obligation or provide administrative oversight.

During the supervision visits, county and sub-county HMTs and CHEWs discussed with CHVs the regular and accurate use of household registers, delivery log books, the commodity tracking tool and referral form, and the BCS+ counseling tools. The visits were used to assess knowledge, application of that knowledge and skills learned, and to resolve gaps identified during the visit. Supervisors were trained on supervision and assessment of standards.

Overall, no major hurdles were experience during the implementation of interventions. However, two challenges affected the pace of activities, namely, erratic supply of FP commodities and inadequate supply of routine data collection forms used by CHVs (MOH 513) and CHEWs (MOH 514). 


\section{Results}

\section{Findings from Observations of CHV-Client Interactions}

\section{Characteristics of $\mathrm{CHVs}$}

At baseline, 212 CHVs were observed and interviewed: 109 in the comparison arm, 66 in the FP arm and 37 in the FP+ Business arm. At endline, a total of $176 \mathrm{CHVs}$ were observed and interviewed: 83 in the comparison arm, 42 in the FP arm and 51 in the FP+ Business arm. Out of the 176, 69 percent were female, about half were between the ages of 40 and 49 (48 percent in comparison arm, 50 percent FP arm and 51 percent FP+ Business arm), and approximately half had secondary education (52 percent in comparison arm, 69 percent $\mathrm{FP}$ arm and 47 percent in FP+ Business arm). More than half were in a monogamous marriage (66 percent in comparison arm, 60 percent FP arm and 59 percent in the FP+ Business arm). Those who said they did not have another occupation other than being a CHV ranged from 39 percent of $\mathrm{CHVs}$ in the FP+ Business arm to 41 percent of the comparison arm and 60 percent of the FP arm. Not all CHVs who were interviewed at baseline were interviewed at the endline. This was because immediately after the baseline, the MoH requested that all the CHVs in the intervention site, totaling 324, be trained in FP-HIV integration. Therefore, there was a wider pool of trained CHVs who were available and willing to be interviewed at the endline.

\section{Quality of integrated FP/HIV services provided by CHVs}

Observation checklists were used to assess improvements in how CHVs initiated and counseled clients. In all the three study arms, a higher proportion of CHVs were observed counseling on the quality of care indicators at endline compared to baseline, as seen in Table 2. For example, significant increases were observed in CHVs who greeted the client in a friendly manner in all three arms ( $\mathrm{p}$-value $<0.01)$ and CHVs who ensured privacy in the comparison and FP arms (p-value <0.01).

Though improvements were seen in most indicators, several measures were still low at endline. For instance, few CHVs were observed discussing gender based violence with clients (22 percent in the comparison arm, 35 percent in the FP arm, and 32 percent in the FP+ Business arm) or giving information on how to use condoms (18 percent in the comparison arm, 38 percent in the FP arm and 14 percent in the FP+ Business arm). Furthermore, only one in three CHVs (27 percent, 41 percent, and 29 percent in the comparison, FP and FP+ Business arms, respectively) were observed emphasizing correct and consistent condom use. Less than half of the CHVs were observed at endline explicitly mentioning to their clients that male and female condoms protect against STIs and HIV (42 percent in the comparison arm and 41 percent in the FP+ Business arm). Significant improvements were observed in the FP arm among the CHVs who explicitly mentioned to their clients that male and female condoms protect against STIs and HIV (from 24 percent at baseline to 62 percent at endline).

Additive indices were developed for each counseling area. Low scores on the index represent lower levels of quality. A statistically significant increase in additive indices for initial CHV-client interactions was seen in all three study arms (comparison arm: 3.01 to 3.73; FP arm: 2.82 to 3.64; FP+ Business arm: 2.75 to 3.53). With regards to discussing risk factors with clients, statistically significant increases were seen in the additive index for the FP arm (1.32 to 2.65) and the FP+ Business arm (1.46 to 2.53). Only in the FP arm was there a significant increase in the additive index (2.15 to 2.90$)$ for $\mathrm{CHVs}$ observed providing information on condoms. 
TABLE 2. QUALITY OF CARE IN OBSERVED CHV/CLIENT INTERACTIONS AT BASELINE AND ENDLINE

\begin{tabular}{|c|c|c|c|c|c|c|}
\hline \multirow[b]{2}{*}{ Quality Indicator } & \multicolumn{2}{|c|}{ Comparison Arm } & \multicolumn{2}{|c|}{ FP Arm } & \multicolumn{2}{|c|}{ FP+ Business Arm } \\
\hline & $\begin{array}{l}\text { Baseline } \\
(n=109)\end{array}$ & $\begin{array}{l}\text { End line } \\
(n=83)\end{array}$ & $\begin{array}{c}\text { Baseline } \\
(n=66)\end{array}$ & $\begin{array}{l}\text { End line } \\
(n=42)\end{array}$ & $\begin{array}{c}\text { Baseline } \\
(n=37)\end{array}$ & $\begin{array}{c}\text { End line } \\
(n=51)\end{array}$ \\
\hline \multicolumn{7}{|c|}{ Does the CHV ensure the following during interaction with their clients? } \\
\hline Greet client in friendly manner & 70.6 & $96.4 * *$ & 62.1 & $92.9 * *$ & 70.3 & $94.1 * *$ \\
\hline Ensure privacy & 82.6 & $98.8 * *$ & 77.3 & $97.6 * *$ & 86.5 & 96.1 \\
\hline Tell client what will be done & 82.6 & 91.6 & 74.2 & 85.7 & 73.0 & 84.3 \\
\hline Tell client to ask questions & 66.1 & $86.8 * *$ & 68.2 & 69.1 & 46.0 & $78.4 * *$ \\
\hline Composite Score (0-4) & 3.01 & $3.73 * *$ & 2.82 & $3.64 * *$ & 2.76 & $3.53 * *$ \\
\hline \multicolumn{7}{|c|}{ Does the CHV discuss the following risk factors with their clients? } \\
\hline Multiple partners & 19.3 & 31.3 & 12.1 & 28.6 & 8.1 & 21.8 \\
\hline STIS & 17.4 & 27.2 & 6.1 & $36.7 * *$ & 21.6 & 29.4 \\
\hline Unprotected sexual intercourse & 30.3 & 39.8 & 13.6 & $45.2 * *$ & 21.6 & 31.4 \\
\hline Gender based violence & 5.5 & 10.8 & 6.1 & 16.7 & 0.0 & 11.8 \\
\hline Composite Score (0-4) & 1.98 & 2.22 & 1.32 & $2.65 * *$ & 1.46 & $2.53 * *$ \\
\hline \multicolumn{7}{|c|}{ Does the CHV mention or provide the following information on condoms to their clients? } \\
\hline Male and female condoms & 45.9 & 48.2 & 43.9 & $73.8 * *$ & 29.7 & $52.9 *$ \\
\hline Protection against STIs and HIV & 36.7 & 42.2 & 24.2 & $61.9 *$ & 18.9 & 41.2 \\
\hline How to use a condom & 13.8 & 21.7 & 12.1 & $38.1 * *$ & 10.8 & 13.7 \\
\hline Correct \& consistent use & 17.4 & 26.5 & 12.1 & $40.5 *$ & 13.5 & 29.4 \\
\hline Composite Score (0-4) & 2.51 & 2.88 & 2.15 & $2.90 * *$ & 2.45 & 2.60 \\
\hline
\end{tabular}

${ }^{\star} p<0.05 ;{ }^{*} p<0.01$

\section{Quality of counseling on STIs/HIV, treatment and care}

CHVs were also observed on their counseling skills related to prevention, detection, and treatment of STIs/ RTIs. Table 3 shows the results from the quality of care measures and an additive index that combines all 10 indicators. Results on quality of care offered by CHVs observed for STI/HIV treatment and care show that while increases were seen for most indicators, proportions were still low at endline, ranging from 2.5 to 3.6 out of a possible 10. There were statistically significant increases for 9 out of 10 indicators in the FP arm and there were significant increases in CHVs observed discussing referral in all three arms.

\section{Family planning counseling}

Quality of care indicators for FP counseling were based on the BCS+ algorithm to assist CHVs in: (1) ruling out current pregnancy; and (2) identifying and discussing client's fertility desires, and are presented in Tables 4, 5 and 6. Table 4 presents the results of pre-FP choice counseling. Statistically significant increases were observed in CHVs asking HIV-positive women about their current contraceptive use in all study arms. While many of the indicators increased significantly, overall endline percentages were low.

Table 5 shows the proportions of interactions of CHVs counseling clients on specific FP methods. There were more statistically significant increases in the methods discussed in the FP and FP+ Business arms than in the comparison arm. The number of methods discussed in a single session increased from one at baseline 
TABLE 3. PROPORTION OF CHV/CLIENT INTERACTIONS OBSERVED FOR QUALITY COUNSELING ON STIS/HIV TREATMENT AND CARE AT BASELINE AND ENDLINE

\begin{tabular}{|c|c|c|c|c|c|c|}
\hline \multirow[b]{2}{*}{ Quality Indicator } & \multicolumn{2}{|c|}{ Comparison Arm } & \multicolumn{2}{|c|}{ FP Arm } & \multicolumn{2}{|c|}{ FP+ Business Arm } \\
\hline & $\begin{array}{l}\text { Baseline } \\
(n=109)\end{array}$ & $\begin{array}{l}\text { End line } \\
(n=83)\end{array}$ & $\begin{array}{l}\text { Baseline } \\
(n=66)\end{array}$ & $\begin{array}{l}\text { End line } \\
(n=42)\end{array}$ & $\begin{array}{c}\text { Baseline } \\
(n=37)\end{array}$ & $\begin{array}{l}\text { End line } \\
(n=51)\end{array}$ \\
\hline $\begin{array}{l}\text { Take client's history and ask for } \\
\text { complaints or complications }\end{array}$ & 33.0 & 28.9 & 27.3 & 35.7 & 29.7 & 41.2 \\
\hline $\begin{array}{l}\text { Discuss risks, e.g. history of STIs/RTIs in } \\
\text { client and partner }\end{array}$ & 16.5 & 26.5 & 7.6 & $31.0 * *$ & 13.5 & 25.5 \\
\hline $\begin{array}{l}\text { Look for signs of STI/RTI, e.g. discharge, } \\
\text { swollen lymph nodes }\end{array}$ & 7.3 & $21.7 * *$ & 0.0 & $23.8 * *$ & 5.4 & $21.6 *$ \\
\hline Identify any danger signs & 11.0 & 19.3 & 9.1 & $26.2^{*}$ & 8.1 & 19.6 \\
\hline $\begin{array}{l}\text { Find out if the client has knowledge of } \\
\text { RTIS/STIS }\end{array}$ & 16.5 & $28.9 *$ & 9.1 & $35.7 * *$ & 16.2 & 27.5 \\
\hline $\begin{array}{l}\text { Find out if client knows how to protect self } \\
\text { from RTIs/STIs }\end{array}$ & 22.9 & 30.1 & 10.6 & $38.1 * *$ & 10.8 & 21.6 \\
\hline $\begin{array}{l}\text { Encourage and facilitate partner referral, } \\
\text { diagnosis \& treatment }\end{array}$ & 21.1 & 26.5 & 7.6 & $40.5 * *$ & 10.8 & 23.5 \\
\hline $\begin{array}{l}\text { Discuss need for screening for STIs } \\
\text { (especially for syphilis) }\end{array}$ & 14.7 & $31.3 * *$ & 12.1 & $35.7 * *$ & 10.8 & 23.5 \\
\hline $\begin{array}{l}\text { Discuss the need for referral of clients } \\
\text { who have HIV }\end{array}$ & 24.7 & $39.8 *$ & 19.7 & $50.0 * *$ & 13.5 & $33.3 *$ \\
\hline $\begin{array}{l}\text { Discuss need for early treatment of STIs \& } \\
\text { avoiding sex if partner has an STI }\end{array}$ & 13.8 & $31.3 * *$ & 15.2 & $42.9 * *$ & 8.1 & 17.7 \\
\hline Composite Score (0-10) & 2.09 & 2.84 & 1.19 & $3.60 *$ & 1.30 & 2.54 \\
\hline
\end{tabular}

${ }^{*} p<0.05 ;{ }^{*} p<0.01$

TABLE 4. PROPORTION OF CHV/CLIENT INTERACTIONS OBSERVED FOR QUALITY OF CARE DURING PRE-FP CHOICE COUNSELING AT BASELINE AND ENDLINE

\begin{tabular}{|c|c|c|c|c|c|c|}
\hline \multirow[b]{2}{*}{ Quality Indicator } & \multicolumn{2}{|c|}{ Comparison Arm } & \multicolumn{2}{|c|}{ FP Arm } & \multicolumn{2}{|c|}{ FP+ Business Arm } \\
\hline & $\begin{array}{l}\text { Baseline } \\
(n=109)\end{array}$ & $\begin{array}{l}\text { End line } \\
(n=83)\end{array}$ & $\begin{array}{c}\text { Baseline } \\
(n=66)\end{array}$ & $\begin{array}{c}\text { End line } \\
(n=42)\end{array}$ & $\begin{array}{c}\text { Baseline } \\
(n=37)\end{array}$ & $\begin{array}{c}\text { End line } \\
(n=51)\end{array}$ \\
\hline Ask whether client is currently using FP & 33.9 & $51.8 * *$ & 28.8 & $59.5 * *$ & 27.0 & $62.8 * *$ \\
\hline $\begin{array}{l}\text { Ask client about her/his satisfaction } \\
\text { with their current method and interest in } \\
\text { continuing or changing }\end{array}$ & 15.6 & $41.0 * *$ & 22.7 & $45.2 * *$ & 13.5 & $47.1 * *$ \\
\hline Ask about history of pregnancy and birth & 6.4 & $20.5 * *$ & 6.1 & $31.0 * *$ & 8.1 & $25.5 *$ \\
\hline Ask desired number of children & 8.3 & $27.7 * *$ & 15.2 & $31.0 *$ & 10.8 & $27.5^{*}$ \\
\hline Ask about date of last menses & 0.9 & $21.7 * *$ & 3.0 & $19.1 * *$ & 8.1 & 9.8 \\
\hline Ask about signs \& symptoms of pregnancy & 1.8 & $15.7 * *$ & 0.0 & $16.7 * *$ & 2.7 & 3.9 \\
\hline Composite Score (0-6) & 0.72 & $1.78 * *$ & 0.85 & $2.02 * *$ & 0.74 & $1.76 * *$ \\
\hline
\end{tabular}

${ }^{\star} p<0.05 ; * \star p<0.01$ 
to three at endline among CHVs in the FP arm. Similarly, the number of methods discussed by CHVs in the FP+ Business arm doubled from baseline to endline (1.12 to 2.50). Discussions around FP methods were highlighted during endline FGDs with HIV-positive clients. Many participants requested FP methods, especially condoms, from the CHVs.

"CHVs ask us what we use during sexual activities, do we use nothing at all or use a protection during sexual intercourse to prevent STI and unwanted pregnancy. For me and my partner we use a condom and also the CHVs have the condoms so that if you want it they give you."

-HIV-positive client, Samia

With regards to skills in FP/HIV integration, statistically significant increases in the proportion of CHVs demonstrating these behaviors were observed in 5 out of 6 indicators in all study arms (Table 6). For instance, the proportion of observations in which CHVs in the FP arm encouraged clients to ask questions during

TABLE 5. PROPORTION OF CHV/CLIENT INTERACTIONS OBSERVED FOR COUNSELING ON SPECIFIC FP METHODS

\begin{tabular}{|c|c|c|c|c|c|c|}
\hline \multirow[b]{2}{*}{ Quality Indicator } & \multicolumn{2}{|c|}{ Comparison Arm } & \multicolumn{2}{|c|}{ FP Arm } & \multicolumn{2}{|c|}{ FP+ Business Arm } \\
\hline & $\begin{array}{l}\text { Baseline } \\
(n=109)\end{array}$ & $\begin{array}{l}\text { End line } \\
(n=83)\end{array}$ & $\begin{array}{c}\text { Baseline } \\
(n=66)\end{array}$ & $\begin{array}{l}\text { End line } \\
(n=42)\end{array}$ & $\begin{array}{c}\text { Baseline } \\
(n=37)\end{array}$ & $\begin{array}{l}\text { End line } \\
(n=51)\end{array}$ \\
\hline Combined pill & 14.7 & $33.7 * *$ & 10.6 & $45.2 * *$ & 13.5 & $41.2 * *$ \\
\hline Progestin only pill & 5.5 & $25.3 * *$ & 10.6 & $35.7 * *$ & 10.8 & $29.4 *$ \\
\hline IUCD & 14.7 & $27.7 *$ & 9.1 & $42.9 * *$ & 13.5 & $33.3 *$ \\
\hline Condom (male or female) & 45.0 & $38.6 * *$ & 24.2 & $66.7 * *$ & 21.6 & $45.1^{*}$ \\
\hline Injectable (Depo) & 26.6 & $31.3 *$ & 15.2 & $54.8 * *$ & 13.5 & $54.9 * *$ \\
\hline $\begin{array}{l}\text { Sterilization (Bilateral Tubal Ligation/ } \\
\text { Vasectomy) }\end{array}$ & 5.5 & $15.7 *$ & 6.1 & $31.0 * *$ & 8.1 & 21.6 \\
\hline Emergency contraception & 6.4 & $13.3 * *$ & 4.5 & $16.7 * *$ & 2.7 & $15.7 *$ \\
\hline Implants & 22.9 & $0.0 * *$ & 12.1 & 2.4 & 18.9 & $0.0 * *$ \\
\hline Composite Score $(0-8)$ & 1.57 & 2.10 & 1.05 & $3.06 * *$ & 1.12 & $2.50 *$ \\
\hline
\end{tabular}

$\star_{p}<0.05 ; * \star p<0.01$

TABLE 6. PROPORTION OF INTERACTIONS WHERE CLIENTS ASKED QUESTIONS AND CHVS SHOWED NON-JUDGMENTAL ATTITUDE AT BASELINE AND ENDLINE

\begin{tabular}{|c|c|c|c|c|c|c|}
\hline \multirow[b]{2}{*}{ Quality Indicator } & \multicolumn{2}{|c|}{ Comparison Arm } & \multicolumn{2}{|c|}{ FP Arm } & \multicolumn{2}{|c|}{ FP+ Business Arm } \\
\hline & $\begin{array}{l}\text { Baseline } \\
(n=109)\end{array}$ & $\begin{array}{l}\text { End line } \\
(n=83)\end{array}$ & $\begin{array}{c}\text { Baseline } \\
(n=66)\end{array}$ & $\begin{array}{l}\text { End line } \\
(n=42)\end{array}$ & $\begin{array}{l}\text { Baseline } \\
(n=37)\end{array}$ & $\begin{array}{l}\text { End line } \\
(n=51)\end{array}$ \\
\hline CHV asks questions & 84.4 & 79.5 & 66.7 & $95.2 * *$ & 64.9 & $92.2 * *$ \\
\hline Encourage client to ask questions & 51.4 & $68.7 *$ & 40.9 & $81.0 * *$ & 46.0 & $76.5 * *$ \\
\hline $\begin{array}{l}\text { Ask tactfully about client's concerns and } \\
\text { answer honestly }\end{array}$ & 43.1 & $57.8 *$ & 45.5 & 59.5 & 48.7 & $80.4 * *$ \\
\hline $\begin{array}{l}\text { Avoid expressing judgement or being } \\
\text { judgmental }\end{array}$ & 48.6 & 62.7 & 37.9 & $73.8 * *$ & 54.1 & $82.4 * *$ \\
\hline $\begin{array}{l}\text { Show attitude favorable to offering several } \\
\text { services in one consultation }\end{array}$ & 41.3 & $61.5 * *$ & 21.2 & $61.9 * *$ & 43.2 & 58.8 \\
\hline $\begin{array}{l}\text { Show confidence in integrating FP/HIV } \\
\text { activities }\end{array}$ & 27.5 & 37.4 & 7.6 & $42.9 * *$ & 18.9 & $52.9 * *$ \\
\hline Composite Score (0-6) & 2.97 & $3.67 *$ & 2.23 & $4.14 * *$ & 2.76 & $4.43 * *$ \\
\hline
\end{tabular}


consultations increased from 41 percent at baseline to 81 percent at endline in the FP arm (p-value <0.01), from 46 percent to 67 percent in the FP+ Business arm (p-value <0.01), and from 51 percent to 69 percent in the comparison arm ( $\mathrm{p}$-value $<0.05)$. A statistically significant increase in the additive score was seen in all three arms.

\section{Aggregate scores on quality of CHVs service delivery}

Aggregate scores were generated to evaluate the overall quality of CHV-client interactions. The maximum number of scores for assessing the provision of integrated FP/HIV services was 42 . Table 7 includes the summary scores for each service component, as set out in Tables 4 to 6 above. Overall, the quality of CHVs' service provision improved significantly, but none of the arms scored more than half of the total score.

TABLE 7. AGGREGATE SCORES ON QUALITY OF CHVS SERVICE PROVISION

\begin{tabular}{|c|c|c|c|c|c|c|}
\hline \multirow{2}{*}{$\begin{array}{l}\text { Quality of service provision by CHVs in } \\
\text { integrating FP/STIs/HIV/AIDS services }\end{array}$} & \multicolumn{2}{|c|}{ Comparison Arm } & \multicolumn{2}{|c|}{ FP Arm } & \multicolumn{2}{|c|}{ FP+ Business Arm } \\
\hline & $\begin{array}{l}\text { Baseline } \\
(n=109)\end{array}$ & $\begin{array}{c}\text { End line } \\
(n=83)\end{array}$ & $\begin{array}{c}\text { Baseline } \\
(n=66)\end{array}$ & $\begin{array}{c}\text { End line } \\
(n=42)\end{array}$ & $\begin{array}{c}\text { Baseline } \\
(n=37)\end{array}$ & $\begin{array}{l}\text { End line } \\
(n=51)\end{array}$ \\
\hline Ensure interaction with clients $(0-4)$ & 3.01 & $3.73 * *$ & 2.82 & $3.64 * *$ & 2.76 & $3.53 * *$ \\
\hline Discuss STI risk factors with clients (0-4) & 1.98 & 2.22 & 1.32 & $2.65 * *$ & 1.46 & $2.53 * *$ \\
\hline $\begin{array}{l}\text { Provide information on condoms to clients } \\
(0-4)\end{array}$ & 2.51 & 2.88 & 2.15 & $2.90 * *$ & 2.45 & 2.60 \\
\hline $\begin{array}{l}\text { Counseled on STIs, treatment and care } \\
(0-10)\end{array}$ & 2.09 & 2.84 & 1.19 & $3.60 *$ & 1.30 & 2.54 \\
\hline $\begin{array}{l}\text { Counseled clients on FP during pre-choice } \\
\text { stage }(0-6)\end{array}$ & 0.72 & $1.78 * *$ & 0.85 & $2.02 * *$ & 0.74 & $1.76 * *$ \\
\hline $\begin{array}{l}\text { Discussed type of FP methods with the } \\
\text { client }(0-8)\end{array}$ & 1.57 & 2.10 & 1.05 & 3.06 & 1.12 & $2.50 *$ \\
\hline $\begin{array}{l}\text { CHVs asked questions by client during the } \\
\text { consultation }(0-6)\end{array}$ & 2.97 & $3.67 *$ & 2.23 & $4.14 * *$ & 2.76 & $4.43 * *$ \\
\hline Total Composite Score & 14.85 & 19.22 & 11.61 & $22.01 * *$ & 12.59 & $19.89 * *$ \\
\hline
\end{tabular}

${ }^{\star} p<0.05 ;{ }^{*} p<0.01$

\section{Results of Interviews with Community Health Volunteers}

Immediately after observations of the CHV-client interactions, CHVs participated in a short interview on the following: information on the services the CHVs provide; number of years they had worked and their work load; update trainings they had completed in various FP and other RH services; their referral practices; and their views and opinions on HIV-related stigma and discrimination, findings of which are in Table 8.

Based on results in Table 8, there were no differences from baseline to endline in how CHVs referred HIVpositive clients for RH or MCH services except in the FP Arm. There was a significant increase from baseline to endline in the proportion of CHVs who reported using referral slips to refer clients to health care facility in the FP arm. There were also significant increases for three out of the four indicators used to assess whether CHVs were not worried about being infected from their HIV-positive clients in the FP arm. Among CHVs in the FP + Business arm, there was a significant increase in those who reported they took the temperature of a patient living with HIV from baseline to endline. There was a higher proportion of CHVs at endline compared to baseline who reported they drew blood from a patient living with HIV in the comparison arm. 
TABLE 8. INTERVIEWS WITH CHVS REGARDING TRAINING AND SERVICE PROVISION AT BASELINE AND ENDLINE

\begin{tabular}{|c|c|c|c|c|c|c|}
\hline \multirow[b]{2}{*}{ Variables } & \multicolumn{2}{|c|}{ Comparison Arm } & \multicolumn{2}{|c|}{ FP Arm } & \multicolumn{2}{|c|}{ FP+ Business Arm } \\
\hline & $\begin{array}{l}\text { Baseline } \\
(n=100)\end{array}$ & $\begin{array}{l}\text { End line } \\
(n=83)\end{array}$ & $\begin{array}{l}\text { Baseline } \\
(n=63)\end{array}$ & $\begin{array}{l}\text { End line } \\
(n=42)\end{array}$ & $\begin{array}{c}\text { Baseline } \\
(n=37)\end{array}$ & $\begin{array}{l}\text { End line } \\
(n=51)\end{array}$ \\
\hline \multicolumn{7}{|c|}{$\begin{array}{l}\text { Proportion of CHVs who indicated how they refer clients seeking various RH services to health facilities or to other units } \\
\text { such as } \mathrm{MCH} / \mathrm{FP} \text { or Comprehensive Care Centers }\end{array}$} \\
\hline Referral slips & 79.8 & 86.7 & 72.3 & $92.9 * *$ & 79.4 & 92.2 \\
\hline Registers & 12.0 & 19.3 & 16.7 & 26.2 & 7.1 & 11.8 \\
\hline Information recorded on client's card & 17.6 & 9.6 & 20.3 & 21.4 & 10.7 & 5.9 \\
\hline $\begin{array}{l}\text { Verbally refer client but do not write } \\
\text { anywhere }\end{array}$ & 22.9 & 13.3 & 37.3 & 21.4 & 29.0 & 15.7 \\
\hline Escort client to clinic & 40.4 & 39.8 & 47.5 & 50.0 & 42.4 & 31.4 \\
\hline Other & 5.6 & 4.8 & 1.7 & 2.4 & 9.7 & 2.0 \\
\hline \multicolumn{7}{|c|}{ CHVs who are NOT WORRIED about getting infected with HIV when... } \\
\hline Touched clothing of patient living with HIV & 86.2 & 83.1 & 87.9 & 83.3 & 86.5 & 90.2 \\
\hline Dressed wounds of patient living with HIV & 44.0 & 56.6 & 22.7 & $54.8 *$ & 51.4 & 58.8 \\
\hline Drew blood from a patient living with HIV & 29.4 & $57.8 *$ & 18.2 & $52.4 *$ & 35.1 & 58.8 \\
\hline Took temperature of patient living with HIV & 67.0 & 73.5 & 43.9 & $71.4 *$ & 62.2 & $88.2 *$ \\
\hline \multicolumn{7}{|c|}{ Availability of written guidelines to protect patients living with HIV from discrimination } \\
\hline $\begin{array}{l}\text { Proportion of CHVs who CONFIRMED the } \\
\text { availability of written guidelines }\end{array}$ & 52.3 & 44.6 & 34.8 & 59.5 & 45.9 & 54.9 \\
\hline \multicolumn{7}{|c|}{ CHVs who DISAGREED with the following statements } \\
\hline $\begin{array}{l}\text { Patients living HIV should feel ashamed of } \\
\text { themselves }\end{array}$ & 42.2 & 41.0 & 43.9 & 40.5 & 48.6 & $25.5 *$ \\
\hline $\begin{array}{l}\text { Most patients living with HIV have had } \\
\text { many sexual partners }\end{array}$ & 41.3 & 45.8 & 34.8 & 40.5 & 51.4 & 35.3 \\
\hline $\begin{array}{l}\text { People get infected with HIV because they } \\
\text { engage in irresponsible behavior }\end{array}$ & 44.0 & 43.4 & 30.3 & 42.9 & 48.6 & 36.0 \\
\hline $\begin{array}{l}\text { HIV infection is punishment for bad } \\
\text { behavior }\end{array}$ & 33.0 & 45.8 & 37.9 & 30.0 & 32.4 & 27.5 \\
\hline
\end{tabular}

\section{Providers' Readiness to Support Integrated Services}

Forty-three health care providers were interviewed at baseline and twenty-eight were interviewed at endline. At baseline, 31 out of 43 providers surveyed were female and worked in $\mathrm{MCH}$ Comprehensive Care Centre (CCC)/ART units. Out of the 43 providers, 16 were Registered Nurse-Midwives (diploma level), 13 were Enrolled Nurse-Midwives (certificate level), 7 were clinical officers and 5 had some other clinical background. Most of the providers, 30 out of 43 , had been working at their current facility between one and five years.

\section{Providers' readiness to offer integrated services at endline}

Results suggest that providers felt that their facility had the necessary support systems in place for providing integrated FP/HIV services. At endline, 22 out of the 28 providers reported receiving in-service training on FP and contraceptive technology in the year preceding the survey. Providers mentioned the use of referral slips and escorting clients to points of care as mechanisms for linking clients to other departments or facilities. 
In addition, 27 out of 28 providers reported that they regularly asked clients about current use of FP methods and discussed FP methods during HIV consultations. Implants and injectables were the most frequently cited FP methods providers reported discussing with women living with HIV; 26 providers reported discussing implants and 25 providers reported discussing injectables. Twenty-four providers reported that staff in the CCC/HIV/ AIDS unit had been trained on FP counseling and method provision. Almost three quarters of providers at endline (20 out of 28 ) reported that their health facility had guidelines on facility-based integrated services, but less than half (11 out of 28) had guidelines on community-based integrated services at endline. Almost all providers (26 out of 28) reported that their facility had an effective referral mechanism between the CHVs and the health staff, and 20 reported that CHVs collected supplies from their facility on a monthly basis. Providers noted that CHVs traveled directly to their respective health facilities to escort clients or receive supplies.

At the end of the study, a sizeable proportion of providers still appeared to hold discriminatory attitudes towards persons living with HIV. For instance, at endline, 12 out of 28 providers felt that people living with HIV should be ashamed of themselves. Seventeen out of twenty-eight providers stated at endline that "people get infected with HIV because they engage in irresponsible behavior." This suggests that continued efforts need to be made at the health facility level, as well as the community level.

\section{Community Unit Readiness for Integrated Services}

CUs in all study arms were selected and assessed on their functionality and readiness to support communitybased integrated FP/HIV services. At baseline, a sample of CUs (22) were interviewed. However, by endline all CUs within each study site (50) were visited and interviewed because the CUs varied in terms of their structure and management. The project examined process, performance and cardinal functionality indicators based on the MoH's National Community Health Strategy.

Process indicators: These include existence of adequate numbers of trained CHVs, CHC members, and CHEWs; availability of necessary equipment such as CHV kits, data tools and referral booklets, performancebased monthly stipends, and bicycles/motorbikes; and supportive supervision by the CHMTs and SCHMTs. At endline, more $\mathrm{CHC}$ members had been trained in FP/RH/HIV specific modules than at baseline. There were no changes at endline in the number of respondents trained in $\mathrm{MNH}$, TB, malaria, or water, sanitation and hygiene. All CUs except one had referral booklets at endline. The $\mathrm{MoH} 513$ tool was available in 20 out of 22 CUs at baseline, compared to 46 out of 50 CUs at endline. Furthermore, at baseline, CHVs at 20 out of 22 CUs reported using the $\mathrm{MoH} 514$ tool, compared to CHVs at 44 out of $50 \mathrm{CUs}$ at endline. There was also a marginal increase at endline in the number of CUs whose CHVs had drug kits, from 6 out of 22 at baseline to 15 out of 50 at endline.

Performance indicators: These indicators encompass the immediate outputs of a functional CU such as: action plans, reporting rate among CHVs, consistency of community dialogue and action days, CHC meetings, CHV monthly feedback meetings, and existence of a sustainability initiative. Most performance indicators at endline did not change when compared to baseline. However, there was an increase in the number of CUs that reported their CHC members held Health Action Days in each of the last 3 months, from 12 out of 22 at baseline to 33 out of 50 at endline.

Cardinal functionality indicators: Cardinal elements of functionality were the "vital signs" of a CU and comprised of the following indicators: 80 percent or more of the CUs' CHVs reporting each month; holding Community Dialogue Days on a quarterly basis; and holding monthly Health Action Days (while this is a process indicator, it is also considered a cardinal functionality indicator). Overall, CUs had good cardinal functionality at 
endline as compared to baseline. For instance, the number of CUs who had at least 80 percent of their CHVs regularly reporting on community activities and visits increased from 16 out of 22 at baseline to 43 out of 50 at endline. Similarly, the number of CUs whose CHCs held monthly feedback meetings in the 3 months preceding the survey increased from 19 out of 22 at baseline to 45 out of 50 CUs at endline.

Assessing CHV retention: Given the voluntary nature of community health workers, and that once CHVs are selected by the community they cannot be replaced unless they retire, die or relocate to another area, active reporting by $\mathrm{CHVs}$ is used to measure their retention rates within a CU. In order to assess whether training of CHCs in business skills and income generation increased the retention of CHVs, we examined data on CHVs' monthly reporting. Data on CHVs' monthly reporting were collected from $\mathrm{CHC}$ records in the comparison, FP and FP+Business arms starting from Janaury 2016 and ending in December 2016.

CHCs in the FP+ Business arm participated in a business skills training in February 2016. CHV monthly reporting rates from January and February 2016 were used to identify the average monthly reporting before the training. Reporting rates from March- December were used to estimate the average after the training. There were significant differences in the average CHV reporting rates between the comparison and FP+ Business arms before and after the intervention. Before the business skills training, the average monthly reporting rate in the comparison arm was 48 percent compared to 97 percent in the FP+ Business arm (p-value 0.000). After the training in February 2016, the average monthly reporting rates was 48 percent and 98 percent respectively (p-value 0.000). There were no significant differences between the FP and FP+ Business arms. Prior to the training, the average reporting rate was 96 percent in the FP arm and 97 percent in the FP+ Business arm, and after the training the average reporting was 95 percent in the FP arm and 99 percent in the FP+ Business arm. The high reporting rates observed in both intervention sites may account for why there were no differences between the two sites after the training.

\section{Clients' Experiences Using Integrated Services}

\section{Characteristics and background of women living with HIV}

A total of 1,609 women living with HIV were interviewed at baseline, with a close-to-even distribution of respondents across the three study arms: 519 in the comparison arm, 555 respondents in the FP arm, and 535 in the FP+ Business arm. Table 9 summarizes the characteristics of women living with HIV at baseline.

The same women were surveyed again 12 months later, although 302 respondents (19 percent) were lost to follow-up, bringing the total sample of women surveyed at endline to 1,307: 409 in the comparison arm, 420 in the FP arm, and 478 in the FP+ Business arm. Reasons why participants were lost to follow up include: study team was unable to reach respondents through contacts provided, the respondent had traveled outside of the study area, and respondent was not interested in being interviewed again.

\section{General health status and use of healthcare by women living with HIV}

Respondents were asked to rate their general health status as seen in Table 10. At baseline, almost half of the women reported their health to be good or very good. The majority of all women reported they had visited a health facility within the last 12 months. The most frequently cited factors hindering access to treatment were cost of treatment and distance/transport to a facility. 
TABLE 9. PROPORTION OF HIV-POSITIVE RESPONDENTS BY BACKGROUND CHARACTERISTICS AT BASELINE

\begin{tabular}{|c|c|c|c|c|}
\hline Characteristic & $\begin{array}{c}\text { Comparison Arm } \\
(n=519)\end{array}$ & $\begin{array}{l}\text { FP Arm } \\
(n=555)\end{array}$ & $\begin{array}{c}\text { FP+ Business Arm } \\
(n=535)\end{array}$ & $\begin{array}{c}\text { Toal } \\
(n=1,609)\end{array}$ \\
\hline \multicolumn{5}{|l|}{ Age** } \\
\hline $18-24$ & 2.7 & 5.6 & 8.1 & 5.3 \\
\hline $25-29$ & 8.9 & 13.3 & 13.5 & 12.0 \\
\hline $30-34$ & 14.1 & 13.2 & 17.4 & 14.9 \\
\hline $35-39$ & 22.0 & 22.5 & 20.4 & 21.6 \\
\hline $40-44$ & 18.9 & 19.3 & 17.2 & 18.5 \\
\hline $45-49$ & 33.5 & 26.1 & 23.6 & 27.7 \\
\hline \multicolumn{5}{|l|}{ Education } \\
\hline None & 15.0 & 12.1 & 12.0 & 13.0 \\
\hline Primary & 73.8 & 76.6 & 73.1 & 74.5 \\
\hline Secondary & 10.8 & 9.9 & 13.8 & 11.5 \\
\hline Tertiary & 0.4 & 1.4 & 1.1 & 1.0 \\
\hline \multicolumn{5}{|l|}{ Religion** } \\
\hline Christian & 98.5 & 97.5 & 93.8 & 96.6 \\
\hline Muslim & 0.5 & 0.9 & 4.3 & 1.9 \\
\hline Traditional/Other & 1.0 & 1.6 & 1.9 & 1.5 \\
\hline \multicolumn{5}{|l|}{ Marital status } \\
\hline Single & 2.7 & 1.5 & 2.9 & 2.4 \\
\hline Living together & 1.7 & 3.8 & 0.9 & 2.1 \\
\hline $\begin{array}{l}\text { Married } \\
\text { (monogamous) }\end{array}$ & 29.7 & 43.2 & 37.6 & 36.8 \\
\hline Married (polygamous) & 17.0 & 17.5 & 19.1 & 17.8 \\
\hline Divorced/separated & 0.6 & 1.3 & 0.6 & 0.8 \\
\hline Widowed & 48.4 & 32.8 & 38.9 & 40.3 \\
\hline \multicolumn{5}{|l|}{ Main Occupation** } \\
\hline Unemployed & 11.4 & 14.0 & 9.5 & 11.7 \\
\hline Employed-Formal & 14.6 & 18.4 & 26.0 & 19.7 \\
\hline Employed-Informal & 65.9 & 60.0 & 56.8 & 60.9 \\
\hline Other & 8.1 & 7.6 & 7.7 & 7.7 \\
\hline \multicolumn{5}{|l|}{ Main Bread Winner** } \\
\hline Myself & 63.8 & 49.9 & 53.8 & 55.7 \\
\hline Partner & 31.2 & 44.9 & 36.1 & 37.5 \\
\hline Parent & 1.7 & 3.1 & 5.6 & 3.5 \\
\hline Other relative & 3.3 & 2.1 & 4.5 & 3.3 \\
\hline
\end{tabular}

${ }^{*} p<0.05 ; * \star p<0.01$ 
TABLE 10. PERCENTAGE DISTRIBUTION OF HIV-POSITIVE RESPONDENTS' BACKGROUND CHARACTERISTICS AT BASELINE

\begin{tabular}{|c|c|c|c|c|}
\hline Characteristic & $\begin{array}{c}\text { Comparison Arm } \\
(n=519)\end{array}$ & $\begin{array}{l}\text { FP Arm } \\
(n=555)\end{array}$ & $\begin{array}{l}\text { FP+ Business Arm } \\
(n=535)\end{array}$ & $\begin{array}{c}\text { Toal } \\
(n=1,609)\end{array}$ \\
\hline \multicolumn{5}{|l|}{ Perception of general health } \\
\hline Very good & 3.0 & 3.2 & 4.5 & 3.6 \\
\hline Good & 45.7 & 42.0 & 45.2 & 44.2 \\
\hline Poor & 40.7 & 42.0 & 39.4 & 40.7 \\
\hline Very Poor & 10.0 & 12.3 & 10.3 & 10.9 \\
\hline Don't Know & 0.6 & 0.5 & 0.6 & 0.6 \\
\hline \multicolumn{5}{|l|}{ Visited health facility } \\
\hline Within 12 months & 88.4 & 89.6 & 87.1 & 88.4 \\
\hline \multicolumn{5}{|c|}{ Problem preventing respondent from seeking care when sick $\dagger$} \\
\hline Getting permission* & 3.5 & 7.6 & 4.7 & 5.3 \\
\hline Money for treatment & 80.0 & 77.0 & 79.3 & 77.7 \\
\hline Distance to facility & 60.7 & 60.4 & 58.3 & 59.8 \\
\hline Transport to facility & 60.9 & 62.2 & 55.3 & 58.5 \\
\hline $\begin{array}{l}\text { Concern about provider's } \\
\text { ability }\end{array}$ & 12.3 & 18.7 & 23.7 & 20.6 \\
\hline Concern provider is unfriendly & 15.2 & 15.3 & 14.8 & 15.1 \\
\hline $\begin{array}{l}\text { Concern about no drugs/ } \\
\text { treatment }\end{array}$ & 33.1 & 30.8 & 33.6 & 32.5 \\
\hline No one to take care of children & 9.8 & 14.1 & 12.9 & 12.3 \\
\hline Not wanting to go alone & 4.4 & 6.5 & 5.8 & 5.6 \\
\hline Other & 2.5 & 2.5 & 2.2 & 2.4 \\
\hline
\end{tabular}

${ }^{\star} p<0.05 ; \star \star p<0.01 ;+$ Multiple answers possible, proportions do not equal 100

\section{Fertility preferences and family planning use at baseline}

Respondents were also asked at baseline about previous pregnancies and fertility desires. Almost all women (96 percent) reported a previous pregnancy; among those respondents $(n=1,248)$, the average number of previous pregnancies was five (including miscarriages and abortions). Among previously pregnant respondents, 44 percent reported that their last pregnancy had been intended, 22 percent reported they had wanted to wait until later, and 34 percent reported that they had not wanted any more children. Only 15 percent of all women surveyed reported they intend to have more children in the future; of those who reported intending to have more children, a majority (76 percent) were between 18 and 24 years old. Women ages 40-49 years had the lowest (4 percent) intention of having children in the future.

At baseline, 69 percent of women reported using an FP method within the 12 months preceding the survey, with no significant differences between the three study arms. Among those who reported using an FP method within the 12 months preceding the survey, 69 percent reported receiving their FP method from a government health facility (77 percent in the comparison arm, 58 percent in the FP arm, and 72 percent in the FP+ Business arm). Only 2 percent of women who used a contraceptive method within the 12 months preceding the survey reported receiving their FP method from a CHV, with no difference between study arms. When asked the main reasons for obtaining FP from the location they had received it, proximity/easy to get to was the most common reason, with 64 percent of women citing this as their main reason. 


\section{Exposure to intervention and quality of services}

Women living with HIV were asked if they had been visited by a CHV in the 6 months preceding the survey and, if so, what SRH/FP-related topics were discussed during the visit. A little over half of the women reported being visited by a CHV in the last 6 months to discuss FP. When asked about certain topics discussed, responses were relatively low for those specific topics and there were no significant increases from baseline to endline (Table 11).

Among clients who reported being visited by a CHV in the last 6 months, between 70 percent and 84 percent reported meeting a $\mathrm{CHV}$ one to five times.

TABLE 11. PROPORTION OF HIV-POSITIVE CLIENTS WHO REPORTED BEING VISITED BY A CHV IN THE LAST 6 MONTHS

\begin{tabular}{|c|c|c|c|c|c|c|}
\hline \multirow[b]{2}{*}{ Variables } & \multicolumn{2}{|c|}{ Comparison Arm } & \multicolumn{2}{|c|}{ FP Arm } & \multicolumn{2}{|c|}{ FP+ Business Arm } \\
\hline & $\begin{array}{l}\text { Baseline } \\
(n=519)\end{array}$ & $\begin{array}{l}\text { End line } \\
(n=409)\end{array}$ & $\begin{array}{l}\text { Baseline } \\
(n=555)\end{array}$ & $\begin{array}{l}\text { End line } \\
(n=420)\end{array}$ & $\begin{array}{l}\text { Baseline } \\
(n=535)\end{array}$ & $\begin{array}{l}\text { End line } \\
(n=478)\end{array}$ \\
\hline $\begin{array}{l}\text { Proportion of clients visited by a CHV in } \\
\text { the past } 6 \text { monthsc }\end{array}$ & 36.5 & $54.3 * *$ & 55.9 & 52.6 & 48.0 & 52.3 \\
\hline $\begin{array}{l}\text { How many times did the } \mathrm{CHV} \text { talk to you } \\
\text { in the past } 6 \text { months? }\end{array}$ & $(n=184)$ & $(n=222)$ & $(n=310)$ & $(n=221)$ & $(n=257)$ & $(n=250)$ \\
\hline 0 & 2.2 & 1.8 & 0.0 & 1.8 & 2.3 & 0.8 \\
\hline $1-5$ & 70.1 & 74.2 & 73.4 & 77.7 & 74.6 & $84.7 * *$ \\
\hline $6-10$ & 20.1 & 17.2 & 18.5 & 13.6 & 14.1 & 8.9 \\
\hline $11+$ & 7.5 & 6.9 & 8.1 & 6.9 & 9.0 & 5.6 \\
\hline $\begin{array}{l}\text { What did the CHV talk to you about during } \\
\text { the visit? }\end{array}$ & $(n=184)$ & $(n=222)$ & $(n=310)$ & $(n=221)$ & $(n=257)$ & $(n=250)$ \\
\hline Ways to prevent HIV transmission & 56.5 & 48.7 & 54.2 & 56.6 & 54.5 & 52.8 \\
\hline Free condoms & 20.7 & 20.7 & 29.4 & 27.2 & 28.8 & 21.2 \\
\hline $\begin{array}{l}\text { HIV care \& treatment, referrals and } \\
\text { adherence }\end{array}$ & 63.0 & 71.6 & 59.7 & 62.9 & 61.1 & 65.2 \\
\hline Family planning & 26.1 & 29.7 & 31.6 & 38.9 & 27.6 & 33.2 \\
\hline Referral to STI testing / counseling & 6.5 & 9.5 & 12.3 & 13.6 & 7.8 & 10.4 \\
\hline Referrals to TB screening & 2.7 & 4.5 & 10.0 & 5.4 & 5.8 & 6.4 \\
\hline Sexual health and rights & 7.6 & 8.6 & 14.5 & 17.7 & 9.7 & 15.2 \\
\hline Gender based violence & 3.3 & 4.5 & 7.4 & $14.9 *$ & 6.2 & 8.8 \\
\hline Relationships & 12.0 & 9.0 & 17.7 & 17.2 & 11.3 & 12.8 \\
\hline
\end{tabular}

${ }^{\star} p<0.05 ;{ }^{*} p<0.01$

\section{Clients' use of family planning services}

Table 12 shows the proportion of HIV-positive women who reported using an FP method in the 12 months preceding the survey, at baseline and endline, and the main methods used. There was a statistically significant increase in the proportion of HIV-positive women who reported using a family planning method from baseline to endline in all three arms $(\mathrm{p}<0.05)$. Respondents reported using mainly injectables (DMPA), implants, male condoms, and female sterilization. Fewer clients used hormonal pills, female condoms, lactational amenorrhea method, withdrawal method, or male sterilization. 
TABLE 12. PROPORTION OF HIV-POSITIVE CLIENTS USING AN FP METHOD IN THE LAST 12 MONTHS

\begin{tabular}{|c|c|c|c|c|c|c|}
\hline \multirow[b]{2}{*}{ Variables } & \multicolumn{2}{|c|}{ Comparison Arm } & \multicolumn{2}{|c|}{ FP Arm } & \multicolumn{2}{|c|}{ FP+ Business Arm } \\
\hline & $\begin{array}{l}\text { Baseline } \\
(n=519)\end{array}$ & $\begin{array}{l}\text { End line } \\
(n=409)\end{array}$ & $\begin{array}{l}\text { Baseline } \\
(n=555)\end{array}$ & $\begin{array}{l}\text { End line } \\
(n=420)\end{array}$ & $\begin{array}{l}\text { Baseline } \\
(n=535)\end{array}$ & $\begin{array}{l}\text { End line } \\
(n=478)\end{array}$ \\
\hline $\begin{array}{l}\text { Proportion of clients who used an FP } \\
\text { method in last } 12 \text { months }\end{array}$ & 67.2 & $76.9 * *$ & 68.8 & $77.4 * *$ & 70.1 & $77.6 *$ \\
\hline Main FP method used in last 12 months & $(n=240)$ & $(n=220) \ddagger$ & $(n=287) \ddagger$ & $(n=217) \ddagger$ & $(n=277) \ddagger$ & $(n=267) \ddagger$ \\
\hline Injectables (e.g. Depo) & 35.0 & 33.6 & 35.9 & 33.5 & 36.6 & 34.9 \\
\hline Male condoms & 25.0 & 16.8 & 21.3 & 21.3 & 21.9 & 14.6 \\
\hline IUD (coil) & 1.7 & 2.3 & 2.2 & 1.7 & 2.3 & 2.9 \\
\hline Implants (e.g. Jadelle, Implanon) & 26.3 & 25.0 & 30.4 & 27.5 & 27.6 & 29.5 \\
\hline Female sterilization (BTL) & 10.0 & 8.2 & 4.8 & 4.7 & 5.3 & 9.3 \\
\hline Others & 2.0 & 3.2 & 5.0 & 3.2 & 5.9 & 3.8 \\
\hline
\end{tabular}

${ }^{*} p<0.05 ; * \star p<0.01 ; \neq$ Missing observations

Information on current use of FP methods was only captured at the endline. Women living with HIV were asked "what is the main FP method that you are currently using?" Approximately half (52 percent) of all women surveyed at endline were currently using a contraceptive method (Table 13). Among those, 19 percent injectables (19 percent) and implants (16 percent), followed by male condoms (10 percent) and female sterilization (4 percent). The use of traditional FP methods was found to be negligible in all study arms.

TABLE 13. PROPORTION OF WOMEN WHO REPORTED CURRENTLY USING AN FP METHOD AT ENDLINE, BY STUDY ARM

\begin{tabular}{|c|c|c|c|c|}
\hline Main FP Method & $\begin{array}{l}\text { Comparison Arm } \\
(n=409)\end{array}$ & $\begin{array}{l}\text { FP Arm } \\
(n=420)\end{array}$ & $\begin{array}{l}\text { FP+ Business Arm } \\
\qquad(n=478)\end{array}$ & $\begin{array}{c}\text { Total } \\
(n=1,307)\end{array}$ \\
\hline $\begin{array}{l}\text { Proportion of clients currently using } \\
\text { a contraceptive method }\end{array}$ & 49.6 & 51.2 & 54.2 & 51.6 \\
\hline Main method currently using & $(n=203)$ & $(n=215)$ & $(n=259)$ & $(n=677)$ \\
\hline Female sterilization & 4.4 & 2.6 & 5.4 & 4.2 \\
\hline Male sterilization & 0.2 & 0.0 & 0.0 & 0.1 \\
\hline Hormonal pill & 0.7 & 1.7 & 1.0 & 1.1 \\
\hline IUD & 1.2 & 1.0 & 1.7 & 1.3 \\
\hline Injectables & 18.1 & 18.8 & 20.5 & 19.2 \\
\hline Implants & 13.4 & 15.5 & 17.4 & 15.5 \\
\hline Male condoms & 9.0 & 11.2 & 8.6 & 9.6 \\
\hline Female condoms & 0.0 & 0.2 & 0.2 & 0.2 \\
\hline Lactational amenorrhea method & 0.0 & 0.0 & 0.2 & 0.1 \\
\hline Fertility Awareness Method & 0.0 & 0.0 & 0.2 & 0.1 \\
\hline Withdrawal & 0.2 & 0.2 & 0.0 & 0.2 \\
\hline Traditional/Herbal/Abstinence & 0.5 & 0.5 & 0.6 & 0.5 \\
\hline Any traditional method & 0.7 & 0.7 & 0.8 & 0.8 \\
\hline Total all FP methods & 49.6 & 51.2 & 54.2 & 51.6 \\
\hline Total modern FP methods & 48.2 & 49.8 & 52.8 & 50.1 \\
\hline
\end{tabular}

${ }^{\star} p<0.05 ;{ }^{*} p<0.01$ 
Among women who were not currently using a contraceptive method, information was sought regarding their future use of FP methods. Approximately 44 percent reported they intended to use a contraceptive method in the future. Among those who intended to use a FP method in future $(n=574)$, the most preferred methods were the injectable (DMPA; 38 percent), implants (33 percent), and male condoms (21 percent).

Among women who reported they intended to use a FP method in the future, 38 percent of women in the comparison arm, 44 percent in the FP arm and 39 percent the FP+ Business arm said that they planned to start using a contraceptive method in the next 12 months after the survey. Among those who reported they did not intend to use an FP method in future $(\mathrm{n}=382)$, the main reasons cited were not being sexually active (48 percent) and infrequent sex (18 percent).

\section{Clients' preference for use of CHVs' services}

At baseline and endline, clients were asked whether they would feel comfortable having CHVs bring them FP methods and the reasons why. As shown in Table 14, the majority of women, in all three arms and at both time points, reported that they would be comfortable with CHVs bringing FP methods to them.

TABLE 14. HIV-POSITIVE CLIENTS' PREFERENCES FOR USING CHV SERVICES

\begin{tabular}{|c|c|c|c|c|c|c|}
\hline \multirow[b]{2}{*}{ Variables } & \multicolumn{2}{|c|}{ Comparison Arm } & \multicolumn{2}{|c|}{ FP Arm } & \multicolumn{2}{|c|}{ FP+ Business Arm } \\
\hline & $\begin{array}{l}\text { Baseline } \\
(n=519)\end{array}$ & $\begin{array}{l}\text { End line } \\
(n=409)\end{array}$ & $\begin{array}{l}\text { Baseline } \\
(n=555)\end{array}$ & $\begin{array}{l}\text { End line } \\
(n=420)\end{array}$ & $\begin{array}{l}\text { Baseline } \\
(n=535)\end{array}$ & $\begin{array}{l}\text { End line } \\
(n=478)\end{array}$ \\
\hline $\begin{array}{l}\text { Proportion of clients comfortable with a } \\
\text { CHV bringing FP methods to them in the } \\
\text { community }\end{array}$ & 73.3 & $84.6 *$ & 78.0 & 85.9 & 71.6 & $90.2 * *$ \\
\hline $\begin{array}{l}\text { Reason for preferring } \mathrm{CHV} \text { to bring } \\
\text { methods to you in the community }\end{array}$ & $(n=318)$ & $(n=54)$ & $(n=380)$ & $(n=73)$ & $(n=324)$ & $(n=83)$ \\
\hline It is convenient & 48.1 & 61.1 & 47.1 & 53.4 & 46.6 & 48.2 \\
\hline The $\mathrm{CHVs}$ are friendly & 11.0 & 13.0 & 18.9 & 12.3 & 14.5 & 13.3 \\
\hline Can receive more than one service & 8.2 & 11.1 & 8.9 & 5.5 & 7.1 & 13.3 \\
\hline Confidentiality and privacy & 12.9 & 5.6 & 13.4 & 6.8 & 16.0 & 8.4 \\
\hline Trusts the $\mathrm{CHVs}$ & 15.1 & 9.3 & 6.8 & $13.7 *$ & 11.4 & 12.0 \\
\hline Other & 4.7 & 0.0 & 4.7 & 8.2 & 4.3 & 4.8 \\
\hline $\begin{array}{l}\text { Level of client satisfaction with services } \\
\text { received from the CHVs }\end{array}$ & $(n=184)$ & $(n=143)$ & $(n=310)$ & $(n=130)$ & $(n=257)$ & $(n=160)$ \\
\hline Very satisfied & 80.4 & 90.2 & 77.4 & 77.7 & 75.5 & $83.8 *$ \\
\hline Somewhat satisfied & 16.3 & 7.7 & 18.7 & 18.5 & 19.1 & 13.1 \\
\hline
\end{tabular}

${ }^{\star} p<0.05 ; * \star p<0.01$

There was an increase in the proportion of respondents who felt comfortable with CHVs providing FP methods in all study arms, but this was only significant in the comparison and FP+ Business arm. The proportion of clients in the FP+ Business arm who reported being "very satisfied" with the services received increased from 76 percent at baseline to 84 percent at endline $(p<0.05)$. There were no statistically significant changes related to client satisfaction from baseline to endline in the other two arms. Most indicated convenience, being able to receive more than one service, perceiving CHVs as friendly and trustworthy, and ensuring confidentiality and privacy as reasons they would be open to receiving FP services from CHVs. 
This perspective also came through in a focus group discussion:

"Yes, CHVs are good. They respect us and if the CHV finds you seated in a crowd and maybe she has something to tell you, she will look for a way to remove you from the crowd and talk to you in private. The CHVs are also confidential, we ask them questions and they answer us according to how we have asked."

HIV-positive client, Samia

\section{HIV-related stigma, discrimination and violence}

Women living with HIV were asked a series of questions related to HIV stigma and discrimination. The intervention did not specifically focus on community-based discrimination, but data were collected to generate evidence to inform training materials for $\mathrm{CHVs}$ and health providers, and for future programs targeted towards minimizing discrimination at the community level. Over the course of 12 months, there was a decrease in the proportion of clients who experienced any form of stigma, discrimination or violence because of their HIV status (Table 15).

There were decreases in clients' own perceptions of living with HIV (perceived internal stigma). In addition, from baseline to endline, there was a 14-percentage point decrease in the proportion of women who were aware of being gossiped about $(\mathrm{p}<0.00)$, and a 12 -percentage point decrease in the proportion of women who were verbally insulted $(\mathrm{p}<0.00)$. A participant in an FGD voiced this opinion:

"Discrimination is there but it is minimal. It is not a big issue. But it could be better if everyone in this community is tested for the HIV virus and know their status." 
TABLE 15. PROPORTION OF CLIENTS WHO REPORTED EXPERIENCING STIGMA AND DISCRIMINATION DUE TO HIV

\begin{tabular}{|c|c|c|}
\hline Variables & $\begin{array}{l}\text { Baseline } \\
(n=1,609)\end{array}$ & $\begin{array}{l}\text { End line } \\
(n=1,307)\end{array}$ \\
\hline Has been aware of begin gossipped about in the past 12 months & 47.8 & $33.4 * *$ \\
\hline Has been verbally insulted in the past 12 months & 36.1 & $24.3 * *$ \\
\hline Has been sexually insulted or forced to have sex & 5.0 & 3.0 \\
\hline \multicolumn{3}{|c|}{ People's attitudes towards people living with HIV make me feel worse about myself $¥ *$ * } \\
\hline Strongly agree & 6.6 & 4.0 \\
\hline Agree & 19.4 & 8.8 \\
\hline Disagree & 38.9 & 54.7 \\
\hline Strongly disagree & 31.7 & 28.1 \\
\hline Don't know & 0.7 & 0.9 \\
\hline \multicolumn{3}{|l|}{ I feel guilty because I have HIV $¥ * *$} \\
\hline Strongly agree & 4.2 & 1.4 \\
\hline Agree & 13.4 & 6.0 \\
\hline Disagree & 54.9 & 66.4 \\
\hline Strongly disagree & 23.9 & 21.7 \\
\hline Don't know & 0.9 & 0.6 \\
\hline \multicolumn{3}{|l|}{ I feel ashamed of having HIV $¥ * *$} \\
\hline Strongly agree & 3.3 & 1.6 \\
\hline Agree & 11.6 & 4.1 \\
\hline Disagree & 51.5 & 64.1 \\
\hline Strongly disagree & 29.8 & 25.6 \\
\hline Don't know & 1.1 & 0.8 \\
\hline \multicolumn{3}{|l|}{ Most people are uncomfortable around someone with HIV $\ddagger^{* *}$} \\
\hline Strongly agree & 5.8 & 24.2 \\
\hline Agree & 25.3 & 54.0 \\
\hline Disagree & 42.3 & 14.2 \\
\hline Strongly disagree & 22.4 & 1.5 \\
\hline Don't know & 1.6 & 2.8 \\
\hline
\end{tabular}

${ }^{*} p<0.05 ;{ }^{*} p<<0.01 ; \neq$ missing observations 


\section{Monitoring of Interventions}

Monitoring tools were used to collect field data from study clients during the intervention phase. Findings, presented in Table 16, show that more women living with HIV were visited by a healthcare worker in the three months preceding the survey in the comparison arm at baseline and endline than in either intervention arm. Among women who were visited by a healthcare worker, the proportion that was visited by and attended to by CHVs increased from 38 percent at baseline to 59 percent at endline in the comparison arm ( $\mathrm{p}$-value $<0.01)$. Although there was an increase in the proportion of women who were visited by a CHV in both intervention arms, the findings were not statistically significant. Specific to FP services, the proportion of clients who reported having been counseled on FP services by CHVs increased from 68 percent to 83 percent in the FP arm (p-value

TABLE 16. PROPORTION OF CLIENT RESPONSES DURING MONITORING VISITS BY STUDY ARM

\begin{tabular}{|c|c|c|c|c|c|c|}
\hline \multirow[b]{2}{*}{ Variables } & \multicolumn{2}{|c|}{ Comparison Arm } & \multicolumn{2}{|c|}{ FP Arm } & \multicolumn{2}{|c|}{ FP+ Business Arm } \\
\hline & $\begin{array}{l}\text { Round } 1 \\
(n=441)\end{array}$ & $\begin{array}{l}\text { Round } 2 \\
(n=44)\end{array}$ & $\begin{array}{l}\text { Round } 1 \\
(n=476)\end{array}$ & $\begin{array}{l}\text { Round } 2 \\
(n=400)\end{array}$ & $\begin{array}{l}\text { Round } 1 \\
(n=312)\end{array}$ & $\begin{array}{l}\text { Round } 2 \\
(n=360)\end{array}$ \\
\hline $\begin{array}{l}\text { HIV+ve clients visited by a health provider } \\
\text { in the last three months }\end{array}$ & 66.7 & 70.7 & 33 & $40.2^{*}$ & 30.0 & 31.7 \\
\hline $\begin{array}{l}\text { No. of women visited by a healtprovider in } \\
\text { the past } 3 \text { months }\end{array}$ & $n=294$ & $n=314$ & $n=163$ & $n=174$ & $n=94$ & $n=114$ \\
\hline Proportion who were visited by a CHV & 37.8 & $59.2 * *$ & 73.6 & 78.7 & 87.2 & 91.2 \\
\hline $\begin{array}{l}\text { Number of women visited by a CHV in the } \\
\text { past } 3 \text { months }\end{array}$ & $n=111$ & $n=186$ & $n=120$ & $n=137$ & $n=82$ & $n=104$ \\
\hline \multicolumn{7}{|l|}{ Type of services given by CHV } \\
\hline FP counseling & 72.1 & 76.3 & 68.3 & $83.0 * *$ & 74.4 & 74.0 \\
\hline HIV counseling & 65.8 & 74.7 & 73.8 & $83.7 *$ & 76.8 & $90.4 *$ \\
\hline FP service provision & 34.2 & 39.8 & 27.0 & $44.2 *$ & 37.8 & 39.4 \\
\hline \multicolumn{7}{|l|}{ FP methods given by $\mathrm{CHV}$} \\
\hline Pills & 0.9 & $0.0 * *$ & 6.4 & $5.4 * *$ & 2.4 & $3.9 * *$ \\
\hline Condoms & 29.7 & $37.1 * *$ & 21.4 & $40.8 * *$ & 35.4 & 36.5 \\
\hline \multicolumn{7}{|l|}{ Clients were asked the following by the CHV: } \\
\hline Whether currently using FP method & 69.4 & 79.0 & 62.7 & $81.0 * *$ & 61.0 & 75.0 \\
\hline Whether satisfied with current method & 54.1 & 61.3 & 55.6 & $69.4^{*}$ & 51.2 & $69.2 *$ \\
\hline Number of children alive & 55.0 & 58.1 & 54.0 & 60.5 & 45.1 & $63.5 *$ \\
\hline Desired number of children & 44.1 & 47.3 & 34.1 & $61.9 * *$ & 34.2 & $58.6 * *$ \\
\hline Timing of next birth & 31.5 & 38.2 & 17.5 & $32.0 * *$ & 23.2 & 33.7 \\
\hline Date of last menses & 48.7 & 60.8 & 23.8 & $53.7 * *$ & 32.9 & $52.9 *$ \\
\hline $\begin{array}{l}\text { Whether they had intercourse since last } \\
\text { menses }\end{array}$ & 36.9 & 41.9 & 19.1 & $36.7 * *$ & 24.4 & 38.5 \\
\hline Counseled on various FP methods & 52.3 & 60.8 & 51.6 & $81.6 * *$ & 56.1 & 66.4 \\
\hline $\begin{array}{l}\text { Informed how method works and its } \\
\text { effectiveness }\end{array}$ & 47.8 & 53.8 & 50.0 & $77.6 * *$ & 58.5 & 62.5 \\
\hline $\begin{array}{l}\text { Referred by CHV to a facility for FP } \\
\text { method }\end{array}$ & 32.4 & $15.1 * *$ & 41.3 & $21.8 * *$ & 42.7 & $23.1^{*}$ \\
\hline Went to the facility they were referred to & 33.3 & $8.6 * *$ & 51.6 & $19.7 * *$ & 65.9 & $24.0 * *$ \\
\hline
\end{tabular}

$\star p<0.05 ;{ }^{*} p<0.01$ 
$<0.01)$. Similarly, the proportion of clients who reported having received FP services from a CHVs increased from 27 percent at baseline to 44 percent at the endline in the FP arm ( $\mathrm{p}$-value $<0.05$ ). The proportion of clients who indicated being referred to a facility for FP methods decreased from baseline and endline in all three arms, with an 8-percentage point decrease in the comparison arm ( $\mathrm{p}$-value $<0.05)$, and a roughly 20 -percentage point decrease in both the FP arm (p-value <0.01) and the FP+ Business arm (p-value <0.05).

\section{Cost Analysis and Incremental Costs for Integrated Services}

\section{Introduction and approach to cost analysis}

An incremental cost-analysis was conducted to estimate the additional health system cost for integrating the provision of pills and condoms into CHVs' existing activities, and the recurrent cost to maintain these additional services. Prior to the intervention, $\mathrm{CHVs}$ were providing some FP services but infrequently. The additional cost for $\mathrm{CU}$ income generation activities was not calculated for the purposes of this analysis. Prior to the intervention, the estimated annual cost per CHV to provide FP services was approximately KES 4,609 (USD\$ 46.09) per CHV. This estimate is based on the proportion of CHV's time spent discussing FP with clients, the average number of pills and condoms provided, and CHEW's time supervising CHV activities. The cost per $\mathrm{CHV}$ and total cost to Busia County were calculated for the initial year, and an average recurrent annual cost was calculated for maintaining CHV provision of pills and condoms to FP clients.

The costing approach assumed that the number of FP clients served was fixed and was based on responses by CHVs at the endline. A three-days training was included in the recurrent annual costs, to ensure effective and quality provision of FP methods by CHVs. The costing approach included the cost of CHEWs' time supervising CHVs' provision of FP services.

The following costs were included in the analysis: 1) training CHVs in FP and integrated HIV services; 2) training of CHEWs; 3) training of CUs in income generation and management activities; 4) allocated supervision of CHVs by CHEWs; 5) provision of pills and condoms; and 6) monthly stipend for CHVs. Cost data were primarily collected from two sources: the training budget and the Kenya Medical Supplies Authority (KEMSA). The training budget was used to identify costs associated with training the CHVs and CHEWs and the cost for condoms and oral contraceptives came from KEMSA. The monthly stipend for CHVs was based on the standard rate paid in Kenya, at KES 2,000 (US\$20) per month, ${ }^{37}$ but allocated at 21 percent for FP service provision based on utilization data that were collected. Similarly, the annual gross pay of the CHEW was allocated to FP supervision based on the same percentage. CHEW salary information was gathered from the Busia County Ministry of Health payroll for financial year 2015-16. Costs are presented both in Kenya shillings (KES) and U.S. dollars (US\$) using a 2016 exchange rate of KES 100 per US\$1.38

To determine whether additional oral contraceptive and condoms would be needed as a result of CHV-provided integrated FP/HIV care, data on CHVs' provision of pills and condoms were collected from a cost-analysis survey. The survey was administered to the same $212 \mathrm{CHVs}$ observed and interviewed at baseline and 176 at endline. In order to conduct a paired t-test analysis to test the hypothesis of no-difference in the mean annual FP visits between the baseline and endline, the study team used data from 29 CHVs who had participated in both the baseline and endline cost-analysis surveys in the FP arm and FP+ Business arms. Results from the two arms were combined to achieve a reasonable sample size. Similarly, data from 23 CHVs who had participated in both baseline and endline cost-analysis surveys in the comparison site were used in the cost analysis. Results from the endline cost survey showed that each $\mathrm{CHV}$ received an average of eight additional clients per month for FP in the FP and FP+ Business arms. Results from the t-test are highlighted below: 
As shown in Table 17, this was 65 annual client visits more than the average number reported at baseline ( $\mathrm{p}$-value $<0.05$ ). In the comparison arm, each CHV received an average of 3 additional clients per month for FP. This resulted in an average of an additional 31 client visits at endline compared to baseline, however this finding was not statistically significant (Table 18). Since the analysis looked at the additional cost for integrating FP services by CHVs, an average of 65 visits per year was used to calculated the additional cost of oral contraceptives and condoms.

TABLE 17. RESULTS OF TEST OF DIFFERENCE IN FP VISITS FOR FP ARM AND FP+ BUSINESS ARM (PAIRED T-TEST)

\begin{tabular}{|c|c|c|c|c|}
\hline Variable & Observation & Mean & Std. Error & Std. Deviation \\
\hline Baseline & 29 & 29.25199 & 12.21108 & 65.75869 \\
\hline Endline & 29 & 94.44032 & 33.51289 & 180.4724 \\
\hline Diff & 29 & 65.18833 & 30.01664 & 161.6446 \\
\hline \multicolumn{3}{|c|}{ Mean $($ diff $)=$ mean $(F P 1-F P 2)$} & & \\
\hline Ho: mean (diff) $=0$ & \multicolumn{2}{|c|}{ degree of freedom $=28$} & & \\
\hline Ha: mean (diff) $<0$ & \multicolumn{2}{|c|}{ Ha: mean (diff) $!=0$} & \multicolumn{2}{|c|}{ Ha: (mean) diff $>0$} \\
\hline $\operatorname{Pr}(T<t)=0.0193$ & \multicolumn{2}{|c|}{$\operatorname{Pr}(|T|>|t|)=0.0385$} & \multicolumn{2}{|c|}{$\operatorname{Pr}(T>t)=0.9807$} \\
\hline
\end{tabular}

TABLE 18. RESULTS OF TESTS OF DIFFERENCE IN CHV VISITS FOR FP SERVICES FOR COMPARISON SITE (PAIRED T-TEST)

\begin{tabular}{l|c|c|c|c}
\hline \multicolumn{1}{c}{ Variable } & Observation & Mean & Std. Error & Std. Deviation \\
\hline Baseline & 23 & 47.83946 & 31.92476 & 153.1058 \\
Endline & 23 & 78.38127 & 3.43003 & 160.3248 \\
Diff & 23 & 30.54181 & 44.15316 & 211.7511 \\
\hline
\end{tabular}

Mean $($ diff $)=$ mean $(F P 1-F P 2) \quad t=-0.6917$

Ho: mean (diff) $=0 \quad$ degrees of freedom $=22$

Ha: mean (diff) < $\quad$ Ha: mean (diff) $!=0 \quad$ Ha: (mean) diff $>0$

$\operatorname{Pr}(T<t)=0.2482 \quad \operatorname{Pr}(|T|>|t|)=0.4963 \quad \operatorname{Pr}(T>t)=0.7518$

\section{Cost of integrating FP services per CHV during initial year and subsequent years}

Table 19 shows the estimated incremental cost for the provision of FP services per one CHV during the year of initial training. After the initial training, CHVs will be given update training every year to ensure they continue to provide FP services (pills and condoms) effectively. In both cases, a stipend for each CHV was assumed to be KES 420 (US\$ 4.29) per month, based on 21 percent of the KES 2,000 (US\$20) stipend for FP service provision. This figure was calculated based on utilization data collected.

The incremental cost was computed by excluding costs already covered under the current CHW program, including the cost of $\mathrm{CHEW}$ time supervising $\mathrm{CHVs}$. The main costs included in this analysis include training, a portion of the CHV stipend for FP visits, and provision of pills and condoms. The incremental cost per CHV is KES 18,174 (US\$ 181.74) in the initial year and KES 12,806 (US\$128.06) in the subsequent year. Excluding the cost of commodities, the cost per CHV in the initial year would be KES 15,110 (US\$151.1) and KES 9,186 (US\$ 91.86) the subsequent year. In the case where the CHV does not receive any stipend, then the total cost would decrease by 5,040 KES (US\$50.40) per CHV. 
Table 19 also displays the total incremental cost of integrating FP into HIV services in Busia County. The assumption used is that there were 184 CUs in Busia County, each with 15 CHVs and 2 CHEWs per CU. The annual cost per CHV is KES 18,174 (US\$ 181.74). Therefore, to calculate the total cost to Busia County, the cost per CHV (US\$181.74) was multiplied by an average of $15 \mathrm{CHVs}$ per CU for each of the 184 CUs in Busia County (2,760 CHVs). This gives the total incremental cost of KES 50,160,240 (US\$ 501,602.40) for the initial year in Busia County. Excluding the cost of commodities, the total incremental cost would be KES 441,598,900 (US\$ 415,989).

With regard to subsequent annual costs for Busia County, the annual cost per CHV for integrating the provision of FP methods into existing CHV activities was KES 12,155 (US\$121.55). Therefore, to calculate the total cost to Busia County, the cost per CHV (US\$121.55) was multiplied by an average of $15 \mathrm{CHVs}$ per CU for each of the 184 CUs in Busia County (2,760 CHVs in the County), giving a total subsequent year cost for Busia County of KES 33,547,800 (US\$335,478.00). The recurrent costs are approximately KES 6,019 (US\$ 60.19) lower per CHV and KES 16,612,440 (US\$ 166,124.40) lower to Busia County. Excluding the cost of commodities, the total incremental cost would be KES 25,325,360 (US\$253,253.60) in the subsequent year.

TABLE 19. INCREMENTAL COSTS DURING INITIAL AND SUBSEQUENT YEARS IN FP ARM AND FP+ BUSINESS ARM

\begin{tabular}{|c|c|c|c|c|c|c|}
\hline Items & $\begin{array}{l}\text { Unit cost } \\
\text { (KES) }\end{array}$ & Unit & $\begin{array}{l}\text { Annual cost } \\
\text { (KES) }\end{array}$ & $\begin{array}{l}\text { Annual cost } \\
\text { per CHV } \\
\text { (US\$) }\end{array}$ & $\begin{array}{c}\text { \# CHVs in } \\
\text { Busia County }\end{array}$ & $\begin{array}{c}\text { Total County } \\
\text { Cost (US\$) }\end{array}$ \\
\hline \multicolumn{7}{|c|}{ Initial year costs for Integrating CHV provision of pills and condoms to FP clients } \\
\hline Initial training (CHEW) & 200 & 1 & 200 & 2.00 & 2,760 & $5,520.00$ \\
\hline Initial training (CHV) & 9,865 & 1 & 9,865 & 98.65 & 2,760 & $272,274.00$ \\
\hline Allocated stipend & 420 & 12 & 5,040 & 50.40 & 2,760 & $139,104.00$ \\
\hline FP pills & 32 & 65 & 2,080 & 20.80 & 2,760 & $57,408.00$ \\
\hline Male condoms & 3 & 266 & 862 & 8.62 & 2,760 & $23,791.20$ \\
\hline Female condoms & 64 & 2 & 127 & 1.27 & 2,760 & $3,505.20$ \\
\hline Total & & & 18,174 & 181.74 & & $501,602.40$ \\
\hline \multicolumn{7}{|c|}{ Subsequent costs to maintain integrated $\mathrm{CHV}$ provision of pills and condoms to FP clients } \\
\hline Update training (CHEW) & 100 & 1 & 100 & 1.00 & 2,760 & $2,760.00$ \\
\hline Update training $(\mathrm{CHV})$ & 3,946 & 1 & 3,946 & 39.46 & 2,760 & $108,909.60$ \\
\hline Allocated stipend & 420 & 12 & 5,040 & 50.40 & 2,760 & $139,104.00$ \\
\hline FP pills & 32 & 65 & 2,080 & 20.80 & 2,760 & $57,408.00$ \\
\hline Male condoms & 3.24 & 266 & 862 & 8.62 & 2,760 & $23,791.20$ \\
\hline Female condoms & 64 & 2 & 127 & 1.27 & 2,760 & $3,505.20$ \\
\hline Total & & & 12,155 & 121.55 & & $335,478.00$ \\
\hline
\end{tabular}




\section{Discussion}

This study demonstrated that CHVs have the potential to integrate the provision of FP services into their regular service provision to women living with HIV. However, the findings showed mixed results in some areas, indicating that additional support and review of the training may be needed to prepare CHVs with the knowledge and skills to provide integrated services. Furthermore, the duration of the study may have been a barrier in observing change.

\section{Feasibility and quality of care}

The quality of CHV service provision improved in some respects among CHVs in the FP and FP+ Business arm, but also in the comparison arm. The quality of service at baseline in the comparison arm was higher (aggregate score of 15) than the FP and FP+ Business arms (aggregate scores of 12 and 13, respectively). However, at endline, there was a significant increase in the aggregate scores for quality of care in the FP and FP+ Business arm. Nevertheless, it is important to note that despite improvements in some areas observed during the CHVclient interactions, the overall quality of care remained low, given that CHVs were observed demonstrating just over half (22) of the 42 indicators included in this study. This suggests the need for continued peer-led practice or supportive supervision in order to increase the quality of CHV service provision, specifically in counseling skills and offering a wide range of FP method choices to clients. Although there was no significant difference in the aggregate score from baseline to endline in the comparison arm, there were significant increase in the quality specific aspects of integrated FP/HIV services, namely, CHV-client interaction, pre-FP choice counseling, and skills in FP/HIV integration. This may be related to other organizations working in the comparison study site (Butula) and the Busia County's overall effort to integrate FP/HIV services.

\section{Provider readiness}

The majority of providers from the study sites were able to provide integrated FP/HIV services and reported that staff in the CCC/HIV/AIDS units were trained in FP counseling and provision, and their health facilities had the necessary systems in place to support community-based integrated FP/HIV services. In addition, 27 out of 28 providers reported regularly asking clients about current FP use and discussing FP methods during HIV-related consultations. Reductions were reported by providers at the endline with regard to stigma and discrimination against HIV-positive clients and from fellow providers. All providers reported that their facilities supported people living with HIV with regard to the provision of integrated FP/HIV services and that they had never observed fellow healthcare workers who were unwilling to take care of clients living with HIV.

Despite the results showing that the majority of providers were familiar with FP/HIV integration issues, providers in the study sites also cited challenges and limitations in the course of their work. Less than half of providers had guidelines on community-based integrated services at endline. Similarly, a sizeable proportion of providers in the study sites held discriminatory attitudes towards persons living with HIV, despite the training on integrated FP/RH/HIV service provision. Other studies have also documented challenges that health providers face in the provision of HIV and FP integrated services. For instance, findings in a recent study in Uganda indicated that providers cited inadequate staff, gaps in knowledge of service providers especially with regard to provision of long-term family planning, limited space, shortage of critical supplies such as HIV test kits, drugs and gloves as examples of the challenges they faced in providing RH/FP/HIV integrated services. ${ }^{39}$ 


\section{Community unit readiness}

A higher number of CUs in the three study arms displayed aspects of readiness for the provision of integrated services at endline than at baseline. Interviews with other players in the health sector revealed that CUs receive technical and administrative support from a variety of actors in the communities where they are located. More providers reported that their health facilities had the necessary systems in place at endline to support community-based integrated FP/HIV services. More CUs had kits, were supplied with condoms, and were using the recommended health information tools such as $\mathrm{MoH}$ 513, MoH 514 and MoH 516 chalk boards at endline compared to baseline. In addition, the number of CHVs who indicated that their CHCs held quarterly meetings increased.

At the endline, respondents drawn from the $\mathrm{CU}$ management committees confirmed that CHVs had been trained in FP, that CUs had plans of action, and CHVs in all CUs covered at least 80 percent of mapped households. In addition, nearly all CHCs had held regular meetings.

There were high monthly reporting rates observed in both intervention arms which make it difficult to assess the potential impact of the business skills training on CHV retention. It was noted that whereas the CHVs reporting rates were fairly uniform in the intervention arms, there were wide fluctuations in the reporting rates in the comparison arm ranging from 22 percent in March 2016 to 80 percent in September 2016. The spike in reporting in September 2016 was attributed to the deployment of a new Coordinator for community healthcare activities in the sub-County, however, this was not sustained since by February 2017 the reporting rate had gone down to 38 percent implying that the measures that may have been put in place were temporary in nature.

\section{Clients' experiences}

Overall, significant changes occurred at the endline, in all three study arms, in the key indicators assessed for clients' use of and access to FP/HIV integrated services. Improvements in the comparison site could be attributed to parallel training activities on HIV, stigma, ARV adherence, defaulter tracing, couple counseling, nutrition, and other HIV-related issues conducted by Rural Education and Economic Enhancement Programme (REEP), a local NGO that is based in Butula sub-county. Further the sub-county HMT in Butula had a regular outreach program for reproductive health services including FP and HIV.

With regard to the current use of FP methods by HIV-positive clients, 52 percent of clients reported using any FP methods. In the 2014 Kenya Demographic and Health Survey (KDHS), 58 percent of married women in Busia County were using any FP method. These results show that the use of FP methods among women living with HIV is slightly lower than among married women in the general population. In an earlier publication, studies in Kenya and Malawi found that 54 percent and 40 percent of women living with HIV, respectively, reported that their last childbirth was unintended, and modern contraceptive use was lower among HIV-positive than HIV-negative women - 26 percent versus 46 percent in Kenya; 19 percent versus 46 percent in Malawi. ${ }^{41}$ In a related study that focused on the use of FP among women living with HIV, ${ }^{42}$ the authors observed that HIVpositive women were more likely to have had an unintended pregnancy compared to HIV-negative women, regardless of their access to FP services. As expected, in terms of method mix, the use of male condoms among women living with HIV was much higher than the general population of married women (9 percent versus 1 percent). The use of implants and injectables among married women was slightly higher in the KDHS 2014 when compared to the current study. However, the use of injectables (DMPA) and implants remained high in both this study and the KDHS 2014 studies. 
Cases of stigma and discrimination against women living with HIV were still reported at endline, though occurrence had decreased. Similar reductions were documented in a recent study conducted in Bangladesh, ${ }^{43}$ which indicated that a targeted stigma reduction intervention can rapidly improve health provider attitudes and increase service satisfaction among young people. A major limitation of the Bangladesh study, however, is that it focused on HIV prevalence among marginalized young people, whereas the current study focused on women living with HIV.

\section{Cost analysis}

As shown in the findings section, the components that were considered for cost analysis are straight forward. However, the issue of paying a monthly stipend to CHVs was not uniform. The cost analysis included the cost for the time spent on FP visits by calculating a percentage of the monthly stipend, which equaled an annual cost of KES 5,040 (US\$ 50.40) per CHV. The stipend was included in the cost model because it is an incentive that could increase $\mathrm{CHV}$ retention and reduce future costs associated with recruiting and retraining CHVs. Additional research on the impact of the stipend on $\mathrm{CHV}$ retention is suggested.

Another issue that emerged from the results was the cost of training CHVs and CHEWs. A three-day refresher training for CHVs and CHEWs was included in the recurrent costs. This was recommended based on the education levels of the CHVs and their knowledge levels at endline. Further research is needed to assess whether yearly refresher trainings would be required and the length of refresher trainings.

The issue of CUs' capacity to generate additional income to cover the costs of integrating FP/HIV services also emerged from the findings. Results from the study showed that CUs have the capacity to integrate FP and HIV services and begin income generation activities. However, it was unclear how much money CUs could generate and whether the money could cover the additional costs of CHV provision of pills and condoms. Further research is required on the capacity of CUs to cover these additional costs.

With regard to scaling up the incremental costs to cover 184 CUs in the entire Busia County, the additional cost in the initial year would be KES 50,160,240 (US\$ 501,602.40), while in the subsequent year, the cost would be KES 33,547,800 (US\$335,478.00). According to Busia County government official documents, the budget estimate for the Ministry of Health for the Financial Year 2017/2018 is KES 1,807,027,960 (US\$ 18,070,279) for both recurrent and development budgetary activities. This implies that the additional cost for the initial year would take 3 percent of the County's budget, while in the subsequent year it will form 2 percent of the County's budget. These are the additional costs required to integrate FP into HIV services by CHVs at the community level. These levels of resources could be mobilized from within the County's budgetary provisions.

\section{Limitations of the Study}

The study had some limitations. First, improvements noted in the comparison site at the endline could be attributed to parallel training activities on HIV-AIDS, including stigma reduction strategies, by a local NGO called Rural Education and Economic Enhancement Programme based in Butula sub-county. Furthermore, the sub-county HMT in Butula had a regular outreach program for reproductive health services, including FP and HIV, supported by partners such as Marie Stopes. In addition, the comparison arm had slightly better quality of care indicators at baseline compared to the FP and FP+ Business arms. 
Second, sample sizes for two of the study populations (clients and providers) were less at the endline when compared to the numbers that had been recruited at the baseline. For instance, 18 percent of clients dropped out of the study by the endline. Since the majority of the women participants were recruited through local networks, we were able to get explanations for the reduction in numbers of clients at the endline. The reasons included some of the clients had presented telephone numbers of their partners and could not be traced at the endline, refusal by some clients, traveling outside the study area in search of employment, and death. Similarly, fewer facility-based health providers were interviewed at endline (28) than had been recruited at the baseline (43). This arose from a labor dispute regarding salaries, during which some health providers did not come into their health facilities.

Third, this study was implemented within a very short period (10 months), from March to December 2016. The short duration of the study makes it hard for the interventions to have an impact on respondents' attitudes and behavior. Fourth, during the course of the project, the supply of contraceptives from the $\mathrm{MoH}$ was erratic. This affected service delivery at both facility and community levels, especially with regard to some of the FP utilization indicators.

Fifth, unavailability of critical tools for collecting health information data, such as $\mathrm{MoH} 513$ (household register), $\mathrm{MoH} 514$ (summary for health indicators) and $\mathrm{MoH} 516$ (the chalk board), resulted in under-reporting of some activities and services at the CHV and CHEW levels. Finally, given the close proximity of CUs in FP arm and FP+ Business arms in Samia sub-county, it is possible that contamination occurred. For example, given that clients have a right to choose their preferred provider, it was possible for a provider in a CU implementing the FP+ Business arm to interact with a client from a neighboring $\mathrm{CU}$ that was implementing the FP arm.

\section{Conclusion and Implications}

Despite the study limitations cited in this report, overall the study demonstrated that CUs are ready to support community-based integrated services. CHVs have the potential to provide integrated FP/HIV services, but will require proper training, updates, and on-going supervisions and feedback.

Specific findings showed that:

- Composite scores for quality of care observed during CHV-client interactions showed improvements in the quality of counseling on FP service provision, STIs/HIV treatment and care, but the quality of care indicators remained low at endline.

- Integration of FP and HIV services at the community level was acceptable to health providers based in the link health facilities.

- The proportion of CHVs who showed attitudes favorable to offering several services in one consultation improved significantly at the endline in all three study arms.

- There was a significant increase from baseline to endline in the proportion of clients who used an FP method in the 12 months preceding survey in all three study arms.

- Nearly all CUs achieved the targets specified in the National Community Health Strategy regarding the functionality of CUs (e.g. timely submission of reports, coverage of at least 80 percent of mapped households, having plans of action, and so forth). 


\section{Recommendations}

- Training of CHVs in integrated FP/HIV should be evaluated to see how it could improve quality of CHV provision of integrated services. Greater attention should be placed on enhancing the quality of care provided by the CHVs and equipping them with necessary reporting tools and FP commodities.

- Effective referral systems need to be put in place between the community and link health facilities, and within departments in the facilities.

- Strategies for reducing HIV-related stigma and discrimination should be incorporated in the in-service training for healthcare providers.

- Sustainability initiatives including Income Generation Activities by CUs should be part of routine monitoring activities of the county and sub-county HMTs 


\section{References}

${ }^{1}$ UNAIDS 2011. World AIDS Day Report. Geneva, Switzerland: UNAIDS

${ }^{2}$ United Nations General Assembly (UNGASS) 2011. Implementation of the Declaration of Commitment on HIV/AIDS and the Political Declaration on HIV/AIDS: Uniting for universal access: towards zero new HIV infections, zero discrimination and zero AIDS-related deaths. New York, USA: United Nations.

${ }^{3}$ Gipson JD, Koenig MA \& Hindin MJ 2008. The effects of unintended pregnancy on infant, child, and parental health: a review of the literature. Studies in FP, 39, 18-38.

${ }^{4}$ Unger JA, Richardson BA, Otieno PA, Farquhar C, Wamalwa D \& John-Stewart GC 2014. Mode of delivery and postpartum HIV-1 disease progression and mortality in a Kenyan cohort. BMC Preg and Childbirth, 14, 257.

${ }^{5}$ Read JS \& Newell MK 2005. Efficacy and safety of cesarean delivery for prevention of mother-to-child transmission of HIV-1. Cochrane Database of Systematic Reviews, 19, CD005479.

${ }^{6}$ Read JS, Tuomala R, Kpamegan E, Zorrilla C, Landesman S, ... et al Women and Infant Transmission Study Group 2001. Mode of delivery and postpartum morbidity among HIV-infected women: the women and infants' transmission study. Journal of Acquired Immune Deficiency Syndromes, 26, 236-45.

${ }^{7}$ Kassebaum NJ, Bertozzi-Villa A, Coggeshall Ms, Shackelford KA, Steiner C, et al 2014. Global, regional, and national levels and causes of maternal mortality during 1990-2013: a systematic analysis for the Global Burden of Disease Study 2013. Lancet, 384, 980-1004.

${ }^{8}$ Lieve VD, Shafer La, Mayanja BN, Whitworth Ja \& Grosskurth H 2007. Effects of pregnancy on HIV disease progression and survival among women in rural Uganda. Tropical Medicine \& International Health, 12, 920-8.

${ }^{9}$ Heffron R, Donnell D, Kiarie J, Rees H, Ngure K, Mugo N, Were E, Celum C, Baeten JM \& Partners in Prevention HSV/HIV Transmission Study 2014. A prospective study of the effect of pregnancy on CD4 counts and plasma HIV-1 RNA concentrations of antiretroviral-naive HIV-1-infected women. Journal of Acquired Immune Deficiency Syndromes, 65, 231-6.

${ }^{10}$ Anand, A., Shiraishi RW, Bunnell RE, Jacobs K, Solehdin N, Abdul-Quader AS, Marum LH, Muttunga JN, Kamoto K, Aberle-Grasse JM \& Diaz T 2009. Knowledge of HIV status, sexual risk behaviors and contraceptive need among people living with HIV in Kenya and Malawi.

${ }^{11}$ National AIDS and STI Control Programme (NASCOP), Kenya. Kenya AIDS Indicator Survey 2012: Final Report. Nairobi, NASCOP. June 2014.

${ }^{12}$ Warren, CE, Mayhew, S. et al (2013): Family planning practices and pregnancy intentions among HIV-positive and HIV-negative postpartum women in Swaziland: a cross sectional survey. BMC Pregnancy and Childbirth 2013, 13:150 http://www.biomedcentral.com/1471-2393/13/150

${ }^{13}$ Central Statistics Office, Swaziland demographic and health survey 2006-07. Maryland USA: MEASURE DHS Macro International Calverton; 2007 
${ }^{14}$ Reynolds H, Steiner M \& Cates W 2005. Contraception's proved potential to fight HIV. Sexually Transmitted Infections, 81, 184-185.

${ }^{15}$ Reynolds H, Janowitz B, Wilcher R \& Cates W 2008. Contraception to prevent HIV-positive births: current contribution and potential cost savings in PEPFAR countries. Sexually Transmitted Infections, 84, ii49-ii53.

${ }^{16}$ Hoffman I., Martinson, F., Powers, K., Chilongozi D., Msiska E., Kachipapa E., Mphande C., Hosseinipour M., Chanza H., Stephenson R \& Tsui A 2008. The year-long effect of HIV-positive test results on pregnancy intentions, contraceptive use, and pregnancy incidence among Malawian women. Journal of Acquired Immune Deficiency Syndromes, 47, 477-483.

${ }^{17}$ Halperin D., Stover J \& Reynolds H 2009. Benefits and costs of expanding access to FP programs to women living with HIV. AIDS, 23, S123-S130.

${ }^{18}$ Stuart G 2009. Fourteen million women with limited options: HIV/AIDS and highly effective reversible contraception in sub-Saharan Africa. Contraception, 80, 412-416.

${ }^{19}$ Wilcher R., Cates W \& Gregson S 2009. FP and HIV: strange bedfellows no longer. AIDS, 23, S1-S6.

${ }^{20}$ Wilcher R \& Cates W 2010. Reaching the underserved: FP for women with HIV. Studies in FP, 41, 125-128.

${ }^{21}$ Reynolds H, Janowitz B, Homan R \& Johnson R 2006. The value of contraception to prevent perinatal HIV transmission. Sexually Transmitted Diseases, 33, 350-356.

${ }^{22}$ Inter-Agency Task Team for Prevention and Treatment of HIV infection in Pregnant Women Mothers and their Children 2012. Preventing HIV and Unintended Pregnancies: Strategic Framework 2011-2015. New York, NY: UNFPA.

${ }^{23}$ FP2020 Rights and Empowerment Working Group. 2014. Family Planning 2020: Rights and Empowerment Principles for Family Planning. Washington, DC: FP2020.

${ }^{24}$ Perry HB, Zulliger R \& Rogers MM 2014. Community health workers in low-, middle-, and high-income countries: an overview of their history, recent evolution, and current effectiveness. Annual Review of Public Health, 35, 399-421.

${ }^{25}$ Creanga AA, Bradley HM, Kidanu A, Melkamu Y \& Tsui AO 2007. Does the delivery of integrated FP and HIV/AIDS services influence community-based workers' client loads in Ethiopia? Heal Pol and Plan, 22, 40414.

${ }^{26}$ Medhanyie A, Spigt M, Kifle Y, Schaay N, Sanders D, Blanco R, Geertjan D \& Berhane Y 2012. The role of health extension workers in improving utilization of maternal health services in rural areas in Ethiopia: a cross sectional study. BMC Health Services Research, 12, 352.

${ }^{27}$ Afework MF, Admassu K, Mekonnen A, Hagos S, Asegid M \& Ahmed S 2014. Effect of an innovative community-based health program on maternal health service utilization in north and south -central Ethiopia: a community-based cross sectional study. Reproductive Health, 11, 28. 
${ }^{28}$ Spaulding AB, Brickley Db, Kennedy C, Almers L, Packel L, Mirjahangir J, Kennedy G, Collins L, Osborne K \& Mbizvo M 2009. Linking FP with HIV/AIDS interventions: a systematic review of the evidence. AIDS, 23, S79-88.

${ }^{29}$ Mak J, I Birdthistle, K Church, N Friend-Du Preez, J Kivunaga, Kikuvi, R Masuku, Integra research team and Susannah H. Mayhew: Need, demand and missed opportunities for integrated reproductive health-HIV care in Kenya and Swaziland: evidence. from household surveys. AIDS 2013, 27 (Suppl 1):S55-S63

${ }^{30}$ Reynolds HW, Liku J, Maggwa, BN, et al. Assessment of VCT Centers in Kenya: Potential demand, acceptability, readiness, \& feasibility of integrating FP services into VCT. Research Triangle Park, NC: FHI, 2003.

${ }^{31}$ Liambila W, Ian Askew, Juma Mwangi, Robert Ayisi, Josephine Kibaru and Saiqa Mullick (2009): Feasibility \& effectiveness of integrating provider-initiated testing and counseling within FP services in Kenya, AIDS 2009, 23 (suppl 1):S115-S121; Wolters Kluwer Health Lippincott Williams \& Wilkins.

${ }^{32}$ Newmann SJ, Grossman D, Blat C, Onono M, Steinfeld R, Bukusi EA, Shade S, Cohen CR (2013). Does integrating family planning into HIV care and treatment impact intention to use contraception? Patient perspectives from HIV-infected individuals in Nyanza Province, Kenya, International journal for gynaecology and obstetrics, 123 Suppl 1:e16-23.

${ }^{33}$ Spaulding AB, Brickley Db, Kennedy C, Almers L, Packel L, Mirjahangir J, Kennedy G, Collins L, Osborne K \& Mbizvo M 2009. Linking FP with HIV/AIDS interventions: a systematic review of the evidence. AIDS, 23, S79-88.

${ }^{34}$ Ministry of Health, Kenya: National Reproductive Health and HIV AIDS Integration Strategy (2009).

${ }^{35}$ Ministry of Health, Kenya (2012): Minimum Package for RH-HIV Integration in Kenya 2012; Printed by the Ministry of Public Health \& Sanitation and the Ministry of Medical Services; Afya House; Nairobi

${ }^{36}$ Liambila W, Chi-Chi Undie, Charlotte Warren, Shiphrah Njeri Kuria, Ruth Wayua Muia, Ruth Ngechu, Jake Koech, Lucy Nguru and Rosemary Kantai 2013: Building the capacity of community midwives and community health workers in financial literacy \& business skills in Kenya.

${ }^{37}$ Jackline O Aridi, Sarah A Chapman, Margaret A Wagah \& Joel Negin (2014): A comparative study of an NGO-sponsored CHW programme versus a ministry of health sponsored CHW programme in rural Kenya: a process evaluation; Human Resources for Health Vol 12, No. 64, BioMed Central.

${ }^{38}$ Central Bank of Kenya rounded off Mean Rate for 2016

${ }^{39}$ Ahumuza SE, Rujumba J, Nkoyooyo A, Byaruhanga R, Wanyenze RK. Challenges encountered in providing integrated HIV, antenatal and postnatal care services: a case study of Katakwi and Mubende districts in Uganda. Reproductive Health. 2016;13:41. doi:10.1186/s12978-016-0162-8.

${ }^{40}$ Kenya National Bureau of Statistics, Ministry of Health/Kenya, National AIDS Control Council/Kenya, Kenya Medical Research Institute, National Council for Population and Development/Kenya, and ICF International. 2015. Kenya Demographic and Health Survey 2014. Rockville, MD, USA: Kenya National Bureau of Statistics, Ministry of Health/Kenya, National AIDS Control Council/Kenya, Kenya Medical Research Institute, National Council for Population and Development/Kenya, and ICF International. 
${ }^{41}$ Anand, A., Shiraishi RW, Bunnell RE, Jacobs K, Solehdin N, Abdul-Quader AS, Marum LH, Muttunga JN, Kamoto K, Aberle-Grasse JM \& Diaz T 2009. Knowledge of HIV status, sexual risk behaviors and contraceptive need among people living with HIV in Kenya and Malawi.

${ }^{42}$ Kimani, J C Warren, T Abuya, R Mutemwa, S Mayhew and I Askew (2015): Family planning use and fertility desires among women living with HIV in Kenya, BMC Public Health 2015, Vol. 15 (909)

${ }^{43}$ Scott Geibel, Sharif M Hossain, et al (2016); Stigma Reduction Training Improves Healthcare Provider Attitudes Toward, and Experiences of Young Marginalized People in Bangladesh, Journal of Adolescent Health, Volume 60 Issue 2, February 2017 


\section{The Evidence Project}

Population Council

4301 Connecticut Avenue, NW, Suite 280

Washington, DC 20008 USA

tel +1 2022379400

Population Council

Avenue 5, 3rd Floor

Rose Avenue

Nairobi, Kenya

evidenceproject.popcouncil.org 